\title{
LA TIPOGRAFÍA COMO TRANSMISORA DE VALORES EN LA CAMPAÑ̃A VISUAL DE LA CONMEMORACIÓN DEL ORGULLO EN MADRID 2017
}

\section{TIPOGRAPHY AS COMMUNICATING AGENT OF VALUES IN THE VISUAL GAMPAING OF WORLD PRIDE MADRID 2017}

\section{MARÍA VANESSA GARCÍA GUARDIA}

Investigadora independiente / Doctora en Comunicación Tlfn: + 34651542147

Email: vanessagarciaguardia@gmail.com

\section{RAFAEL TIMÓN GÓMEZ}

Profesor de Comunicación

Facultad de Ciencias Jurídicas y Económicas. Universidad Isabel I de Castilla

C/ Fernán González, 76 (España) Burgos 09003

Tlfn: + 34690680512

Email: rafael.timon@ui1.es
PALABRAS CLAVES

Tipografia, World Pride, Madrid, semiótica, New Ugly, campaña visual
KEY WORDS

Typograpy, World Pride, Madrid, semiotics, New Ugly, visual campaign 


\title{
Resumen
}

La reciente fiesta del Orgullo 2017, acontecida en Madrid, fue publicitada mediante una campaña con la que el Ayuntamiento quería transmitir una serie de valores que consideraba que hacían perfecta a la ciudad para esta celebración: la diversidad, la diferencia, la ruptura, o el reconocimiento de la libertad de expresión. Esta comunicación quiere analizar el principal recurso que el estudio al que se encargó el trabajo utilizó para transmitir esos valores: la tipografía, con el objetivo de mostrar cómo los tipos, aun con siglos de historia a sus espaldas, pueden ser usados para evocar conceptos cercanos a nociones como transgresión o contradicción. Lo hace analizando la capacidad sígnica de la tipografía para connotar, desde una perspectiva, por lo tanto, cercana a la semiótica. Pero también, conectando el estilo tipográfico de la campaña con un movimiento contemporáneo en el diseño gráfico, como el New Ugly, que permite a los diseñadores escapar de la utilización de ciertas fórmulas que caen en la estereotipia a la hora de representar estéticamente al colectivo LGTBIQ (el repetido uso de los colores de la bandera arcoíris o la fotografía) y transmitir una imagen más fresca y renovada del evento y de la ciudad de Madrid.

\begin{abstract}
The city council of Madrid launched an advertising campaing for the World Pride Madrid 2017 based in some values related with their understanding of the spirit of the city: diversity, openness, freedom... They thought that this values make the city perfect for this celebration. This paper analyses the main resource of this campaing: typography, with the aim to show how typographic characters can be used to evoke notions like transgression or contradiction, even after five centuries of tipographic rules. It uses a semiotic perspective to analyzes the ability of typography to connote, that is, to communicate go further the linguistic message. At last, the paper wants to connect the tipographic family used in the advertising campaing with a contemporary aesthetic movement, the New Ugly. This movement means a breakdown with traditional aesthetic forms in order to generate new ways of expression, that here generates a freshly way of represent the LGTBIQ collective, go further of the use of the rainbow flag or stereotyped photographic images.
\end{abstract}




\section{Introducción}

La presente comunicación pretende analizar el uso tipográfico de la campaña visual del World Pride Madrid 2017 desde una perspectiva semiótica, para desentrañar sus valores comunicativos como signo plástico y su utilización por parte de los creadores de la misma. En un contexto (el de las celebraciones del World Pride) donde prima el color y lo figurativo, esta campaña reivindica la expresividad de la tipografía como transmisora de significación más allá de, y también junto al, mensaje lingüístico que transporta.

\section{Objetivos}

El objetivo del análisis es desentrañar la forma en que un trabajo tipográfico complejo, como es el de la campaña desarrollada por Koln Studio para el Worl Pride Madrid 2017, puede transmitir significados por sus cualidades plásticas, y la vigencia o efectividad de una propuesta como ésta en un ámbito saturado de imágenes como es el de la publicidad.

\section{Metodología}

La metodología empleada será semiótica, ya que ésta permite un acercamiento a los valores comunicativos de la tipografía y cómo éstos se relacionan con el significado de palabras y frases. Ello requiere de varias fases de estudio. Siguiendo la ya clásica obra de Bringhurst, Los elementos del estilo tipográfico (2014), podemos establecer tres: descripción de los elementos formales de la tipografía, elección de la misma y efectos de esa elección. La primera fase es asumible desde el punto de vista externo al diseñador. En la segunda sólo podremos recurrir a las intenciones de los diseñadores (información de la que, efectivamente, disponemos), donde nos fijaremos en dos elementos de esa elección: la relación con el tema y la función de la pieza donde se ha utilizado la tipografía. Por supuesto, esa información no puede ser definitiva, sino que se tercia un análisis externo para determinar si los diseñadores han conseguido su objetivo, y nos introduce en la tercera fase. En ese sentido, deberemos abordar dos aspectos: la relación de la tipografía con el mensaje lingüístico y todo aquello que va más allá de él y que: "da la razón a la presencia de un valor semiótico en la tipografía" (Pérez Peña, 2010, p. 14), es decir, a que la tipografía como signo visual comunica por si misma, independientemente del mensaje lingüístico. Para ello se utilizarán los planteamientos del grupo de retóricos y semióticos belga autodenominado Groupe $\mu$, consignados en su Tratado del signo visual (1992), que analizan el signo plástico desde su forma (dimensión, posición y orientación), textura (tridimensionalidad, tactilomotricidad y expresividad) y color (saturación, dominancia y luminosidad).

\section{1. ¿Qué podemos entender por tipografía?}


La definición de lo que se puede considerar como tipografía es una labor compleja. Para Baines y Haslam (2002, p. 6): "La tipografía se ocupa de estructurar y organizar el lenguaje visual. El diseño de tipos se ocupa de la creación de las unidades que deben organizarse, los caracteres que constituyen un tipo", así que, finalmente, entienden que tipografía es la: "notación y organización mecánica del lenguaje" (2002, p. 7). Por lo tanto, la tipografía se diferencia de la escritura o la rotulación en el factor mecánico, que actualmente se ha trasladado, como muchos otros, al ámbito digital. De esta forma, la tipografía refleja el espíritu de una época en la manera en que la tecnología y el discurrir estético se aplica a la escritura. Como explican Martín Montesinos y Mas Hurtuna: "la evolución de la escritura es un mapa donde se pueden observar los cambios que experimenta la orientación intelectual del hombre, porque el hombre transporta los cánones de su concepción del mundo a la forma de los caracteres" (2001, p. 46).

La tipografía es técnica y requiere de tecnología, pero también es lenguaje y, por lo tanto, comunicación, ya que: "media entre el contenido de un mensaje y el lector que la recibe" (Jury, 2007, p. 8), y por último, es una realidad plástica que, como todas, ostenta forma, color y textura. Es desde esta triple perspectiva que hay que analizarla, ya sea atendiendo a cada una por separado o a la forma en que se interrelacionan.

\section{Cualidades físicas de la tipografía}

Para el estudio de las cualidades físicas de la tipografía, o aspectos formales de la misma, se puede atender a la observación de la familia tipográfica. Bailes y Haslam (2002, p. 48) establecen una serie atributos formales para describir una tipografía, entre los que vamos a considerar el peso o espesor, la modulación, las terminales o serifas, la proporción y, por último, la anatomía.

Los tres primeros atributos atienden a un aspecto esencial: el trazo o línea que da forma a las letras. Dentro del trazo podemos identificar dos cualidades: espesor y modulación, la primera de las cuales dará lugar al color, es decir, a cómo de oscura y ligera se puede ver la tipografía en el texto. En cuanto a la modulación, se refiere a la forma en que el grosor del trazo cambia en las diferentes partes de la letra, lo que también condiciona la inclinación de la letra respecto de su eje. Por último, el trazo de una letra puede terminar en una pequeña cuña que se denomina serifa. Su presencia o ausencia divide las familias tipográficas en serifs y san serifs (sin serifa), y algunos diseñadores consideran que las familias serifs son más legibles al crear la serifa una línea en la base de la letra que da mayor continuidad a la línea de texto.

Como se ha indicado, el aspecto de una familia tipográfica está también condicionado por sus proporciones, que se corresponden con las dimensiones básicas de la letra y el uso del espacio, es decir, con la altura y la anchura de la misma. Así, algunas letras se caracterizan por una altura condensada (estrechas y altas), mientras que otras lo hacen por unas formas extendidas (anchas y bajas). La proporción también está condicionada por la altura de la $x$ (ver imagen 2.1), que consiste en la línea imaginaria que se crea a partir de la altura de las letras de caja baja (minúsculas). Cualquier parte de las letras de caja baja que está por encima 
del $x$-height se llama ascendente, mientras que todo aquello que queda por debajo de la línea base de las letras será la descendente.

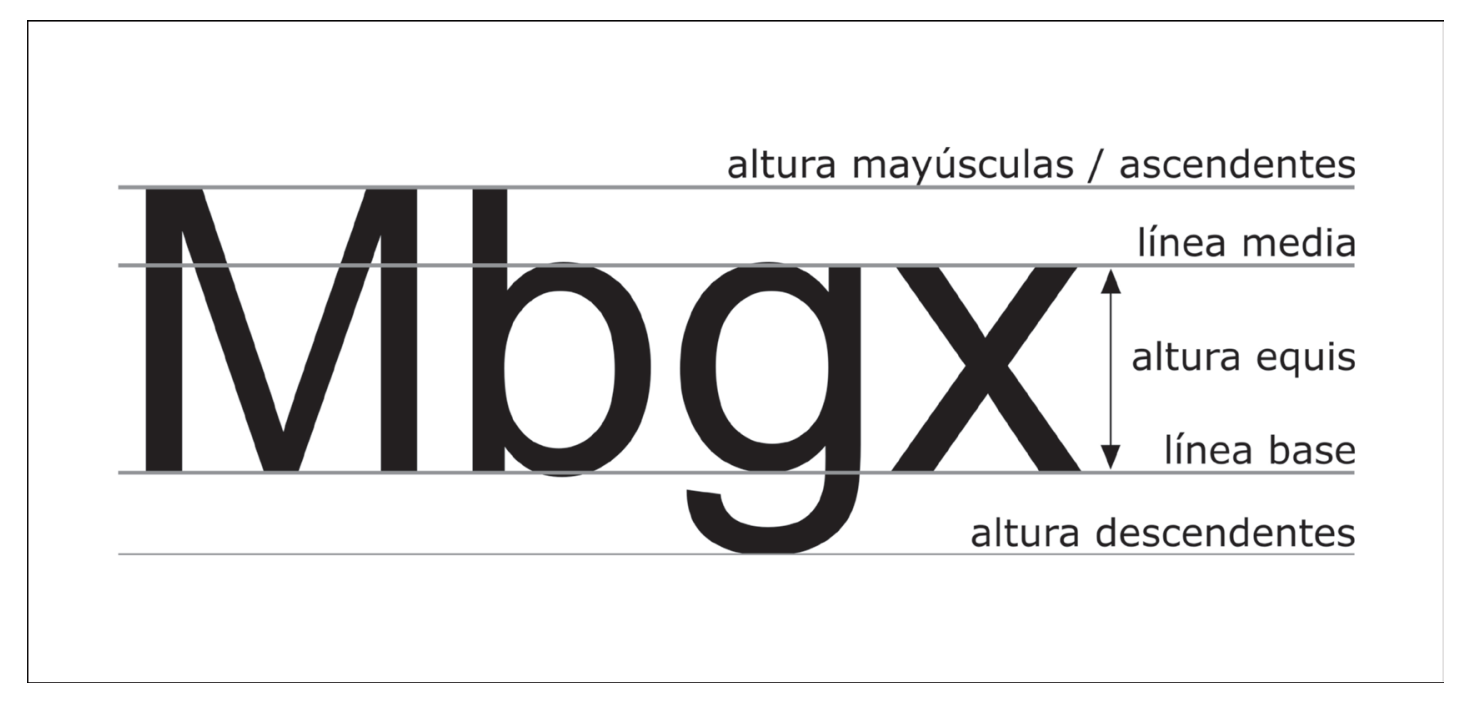

Imagen 2.1: diagrama de las alturas de los caracteres (Fuente:

http://letrascalvas.blogspot.com.es/2015/12/ud-4-post-de-teoria.html)

Los caracteres ostentan unas formas básicas, que son las que las definen, pero como indican Martín Montesinos y Mas Hurtuna (2001, p.78), desde el momento en el que aparecieron éstas hasta la actualidad, los caracteres han adquirido múltiples rasgos anatómicos, algunos de los cuales se han vuelto imprescindibles y otros resultan decorativos. Así, para estos autores, los rasgos esenciales en un carácter y, por lo tanto, a los que es necesario aludir para describirlo son (ver imagen 2.2):

- Asta o fuste: parte principal del trazo. Es el trazo vertical principal que configura la estructura de la letra.

- Ascendente: parte de las letras de caja baja que se extiende por encima de la altura de la altura $\mathrm{x}$ (ojo medio), como en la letras b o d.

- Descendente: parte de los caracteres de caja baja que se prolonga por debajo de la línea base, como en las letras $g$ o $p$.

- Brazo: trazo horizontal o diagonal que sale de otro vertical, como ocurre en las letras E.

- Filete o perfil: trazo horizontal entre verticales, diagonales o curvas, como en la letra e o A.

- Cruz o travesaño: línea horizontal que cruza por algún punto el trazo principal, como en la letra t of.

- Panza o bucle: trazo curvo. 
- Hombro o arco: trazo curvo que se prolonga desde un asta en algunas letras sin cerrarse. Lo tienen la h, la mo la $\mathrm{n}$.

- Espina o doble arco: trazo curvo principal que desciende de izquierda a derecha en la letra s.

- Ojal superior e inferior: línea que constituye la curvatura en la parte superior e inferior de la g de caja baja.

- Cuello: trazo que une la cabeza con la cola de la g.

- Cola: prolongación inferior de algunos caracteres, como en la Q.

A estos rasgos se le pueden sumar otros opcionales, entre los que Martín Montesinos y Mas Hurtuna (2001, p.80) destacan:

- Terminal, remate o gracia: breves trazos iniciales o finales que se dan en ciertos caracteres y que no proyectan en la dirección del trazo donde se sitúan, cerrándose en sentido perpendicular o con alguna inclinación. Pueden ser: en bloque, en punta, redondeados, una fina línea, con rasgos muy abruptos, etcétera.

- Uña, gancho, espolón o ápice: final de un trazo que no acaba en remate, sino con una pequeña proyección del trazo.

- Lágrima, gota o botón: final de un trazo que termina en una forma redondeada.

Así, el uso adecuado de los aspectos formales de los caracteres tipográficos está íntimamente relacionado con su legibilidad, es decir, con la capacidad para ser diferenciados. Tradicionalmente, los tipos que se han considerado de más fácil lectura son aquellas fuentes diseñadas de acuerdo a parámetros tradicionales, con grandes blancos interiores y contraformas (espacios cerrados o semicerrados de las letras), utilizada a tamaño suficiente y con un contraste tonal adecuado entre letra y soporte (que no ha de ser ni muy oscuro ni muy brillante) (Jury, 2006, p. 82). 


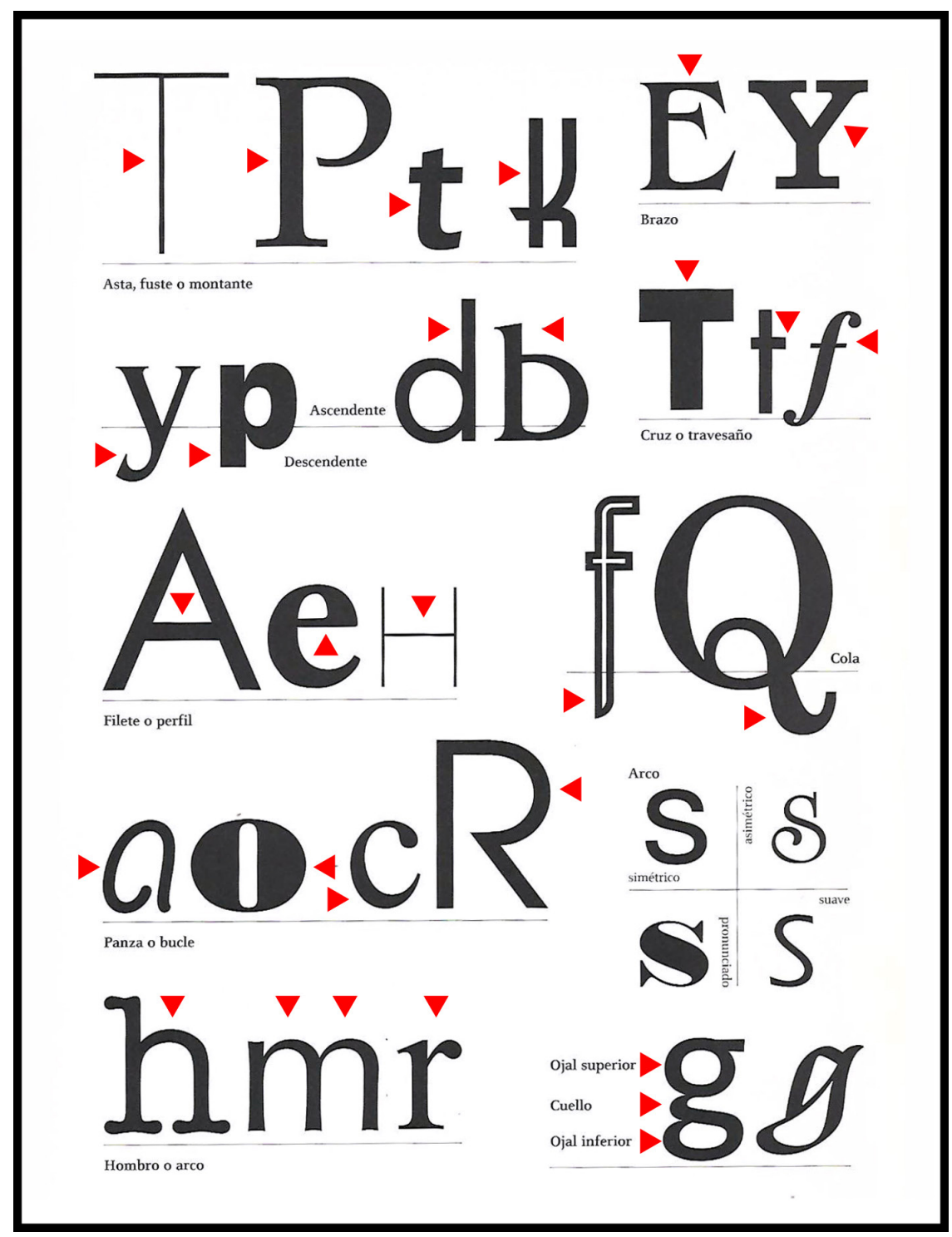

Imagen 2.2: anatomía del tipo (Fuente: Martín Montesinos y Mas Hurtuna, 2001, p. 79)

\section{Tipografía experimental y expresiva}

La descripción de los aspectos formales de la tipografía atiende a lo denotativo o informativo, es decir, a los aspectos relacionados con su eficacia como vehículo del mensaje lingüístico. Sin embargo, todo uso de la tipografía va acompañado de un mensaje connotativo o que transmite un significado persuasivo. El aspecto connotativo de la tipografía es más evidente en el caso de las tipografías de tipo expresivo, aquéllas que incorporan recursos plásticos con el objetivo de transmitir sensaciones. De esta manera, a través de la intervención en las distintas variables de los caracteres se consigue difundir ideas de distinto calado significativo y emocional. 


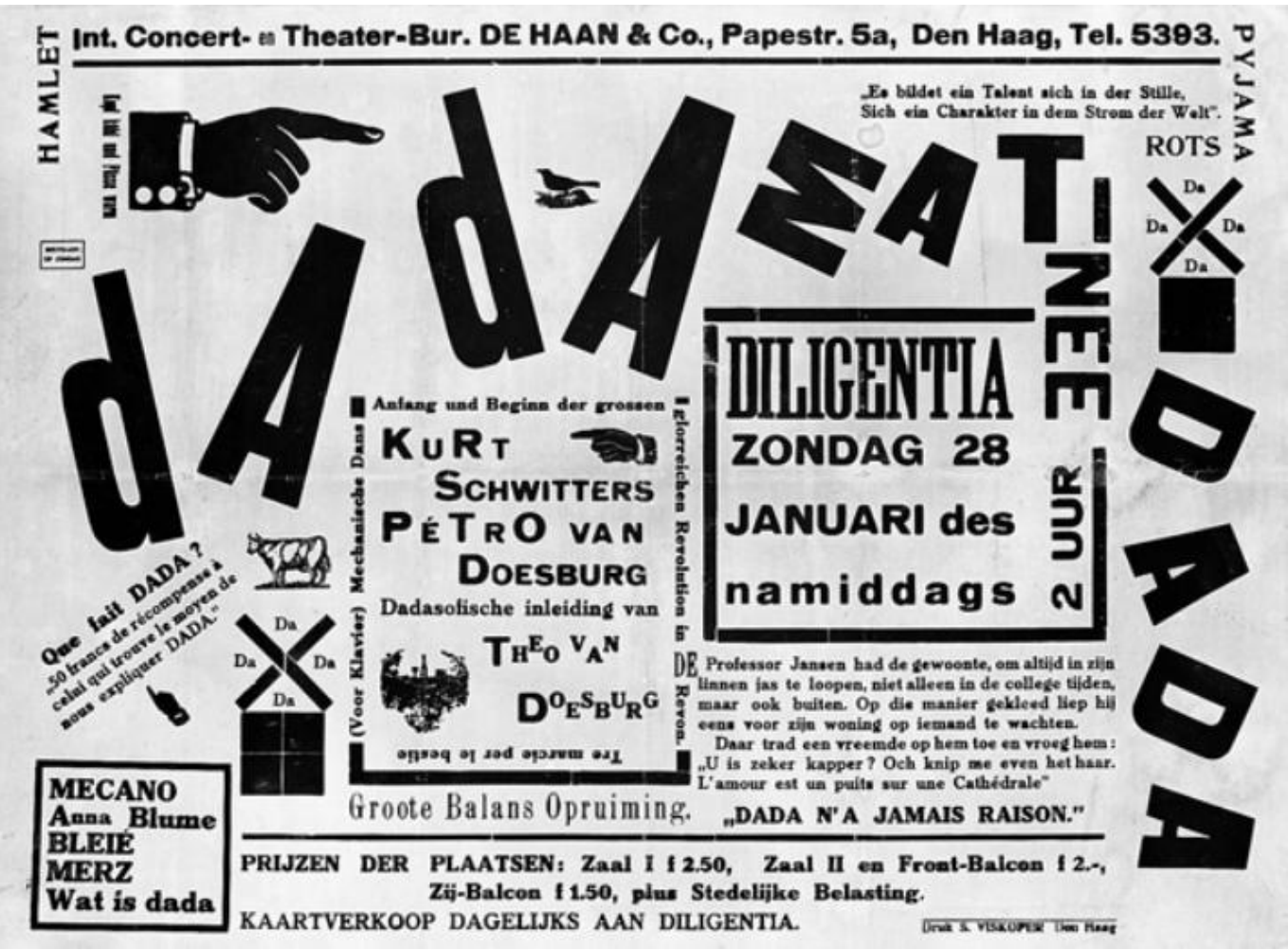

Imagen 3.1: Poster for Dada Matinée - Theo_van_Doesburg (Fuente: Wikipedia)

Existen numerosos ejemplos en la historia tipográfica que explotan sus cualidades expresivas, siendo, tal vez, los más relevantes los experimentos llevados a cabo por las vanguardias artísticas, concretamente, por el dadaísmo (imagen 3.1), el futurismo (imagen 3.2) y el constructivismo ruso. De todas formas, se pueden identificar esfuerzos anteriores que buscan algo más que la claridad y la legibilidad, como son las aportaciones de Bodoni o Baskerville, que desarrollan tipos históricos y ornamentos que atienden a una visión estética de la tipografía. Jury apunta que: "durante los experimentos de los años veinte y treinta, los tipógrafos trataban de crear unos medios de comunicación nuevos, más libres, flexibles y visibles, con los que hacer frente a los retos sin dejarse llevar por las afectaciones estilísticas del pasado" (2007, p. 30). 


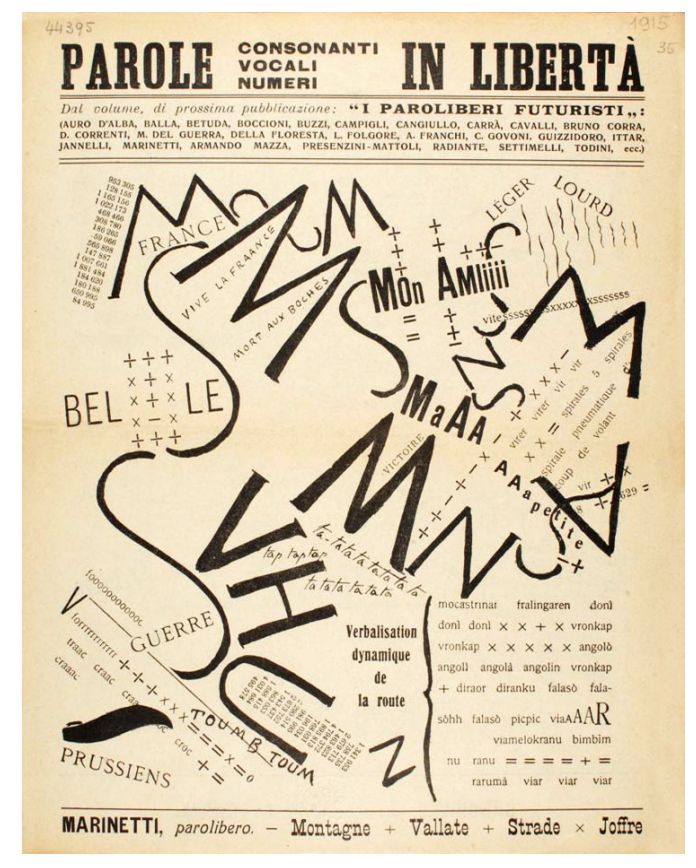

Imagen 3.2: Montagne + Vallate + Strade x Joffre - F. T. Marinetti (Fuente: Wikipedia)

Pero con la expansión de los procedimientos y concepciones acuñadas en la Escuela de la Bauhaus, se impone una visión funcionalista de la tipografía que se consolida con la escuela suiza y que prima la legibilidad, influyendo a gran parte de los tipógrafos y los diseñadores editoriales hasta los setenta. Diseñadores como Herbert Bayer, que trabajó en la Escuela, o Jan Tschichold, adscrito a la Escuela de Munich, promulgaron la búsqueda de la belleza útil en tipografía, apostando por familias sans serif basadas en estrictas formas geométricas y muy lejanas de la libertad y expresividad por la que abogaban las vanguardias.

Solo fuera de la academia, y de forma limitada, se encuentran aportaciones que rompen con esa tendencia: el pop art, la psicodelia (ver imagen 3.3) o el punk, ya entrados los años setenta. En los ochenta el posmodernismo trajo un nuevo interés por la experimentación, aunque con una intención contraria a la de las vanguardias. Mientras que las vanguardias querían romper con lo que existía, el posmodernismo no quiere romper con nada, sino "estar bien con todo" (Filpe y Guitelman, s.f.), (ver imagen 3.4). Esa falta de confrontación, la velada noción de que la experimentación es un juego, la propensión a la banalidad, etcétera, hicieron de las experimentaciones posmodernas algo fácilmente digerible que rápidamente se comercializó y se despojó de cualquier poder de transgresión (el ejemplo más palpable podría ser la MTV). Pero esas estrategias calaron hondo en muchos diseñadores, constituyendo poco después un verdadero movimiento estético con implicaciones en la tipografía, como es el New Ugly. Éste es un movimiento ecléctico que reacciona ante los principios asociados al buen diseño y que: "valiéndose de múltiples recursos (referencias al pasado, combinación de elementos digitales y analógicos, recurso a la ironía o inclusión de motivos populares, entre otros), introduce deliberadamente una falsa apariencia de imperfección o dejadez" (Suárez Carballo, Martín San Román y Galindo Rubio, 2014, p. 24). Así, el New Ugly se siente cómodo en la imprecisión, el error manifiesto y el carácter experimental, y se centra en la expresividad a costa de la funcionalidad y la eficacia comunicativa (Poynor, 2003, p. 171). 


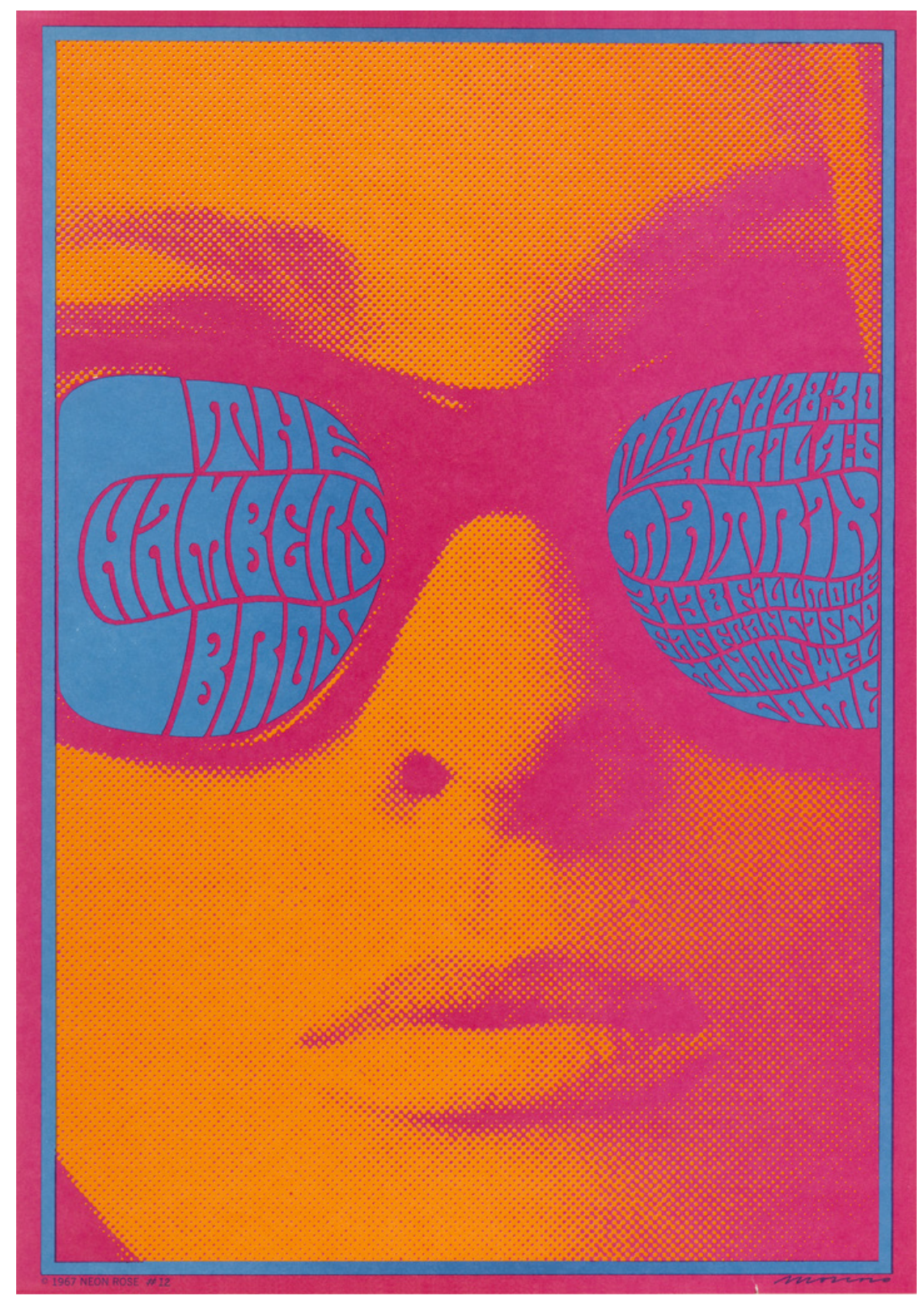

Imagen 3.3: Chambers Brothers Band (Neon Rose \#12) - Victor Moscoso (Fuente: Cooper Hewitt) 


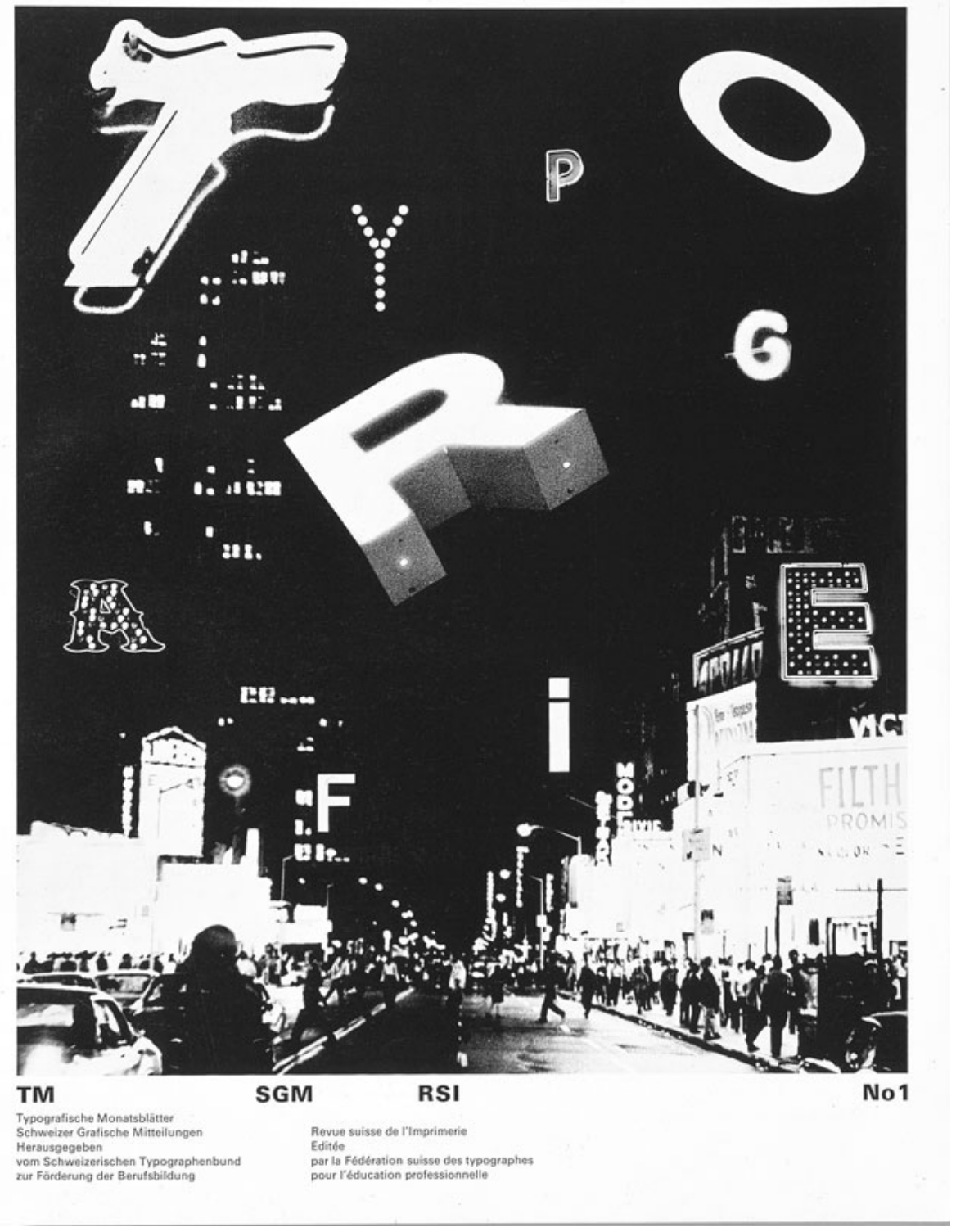

Imagen 3.4: 1971 issue 1 cover - Dan Friedman (Fuente: http://www.tm-research-archive.ch/issue/1971-1/)

Desde una perspectiva tipográfica, Suárez Carballo, Martín San Román y Galindo Rubio (2014), en su estudio sobre la cuestión, concluyen que no hay un componente tipográfico que pueda relacionarse de forma unívoca con el movimiento, sino que es la tendencia a la libertad en la asociación semántica de la forma tipográfica, la distorsión de los caracteres (aunque no en un sentido único), la preponderancia de lo emocional frente a lo funcional, el escaso interés en la legibilidad, la apuesta por las mayúsculas y los tamaños grandes, el uso de efectos gratuitos de apariencia kitsch y escasa capacidad comunicativa y la fusión entre lo antiguo y lo moderno, o lo analógico y lo digital, lo que caracteriza el uso tipográfico en el New Ugly (ver imágenes 3.5 y 3.6$)$. 


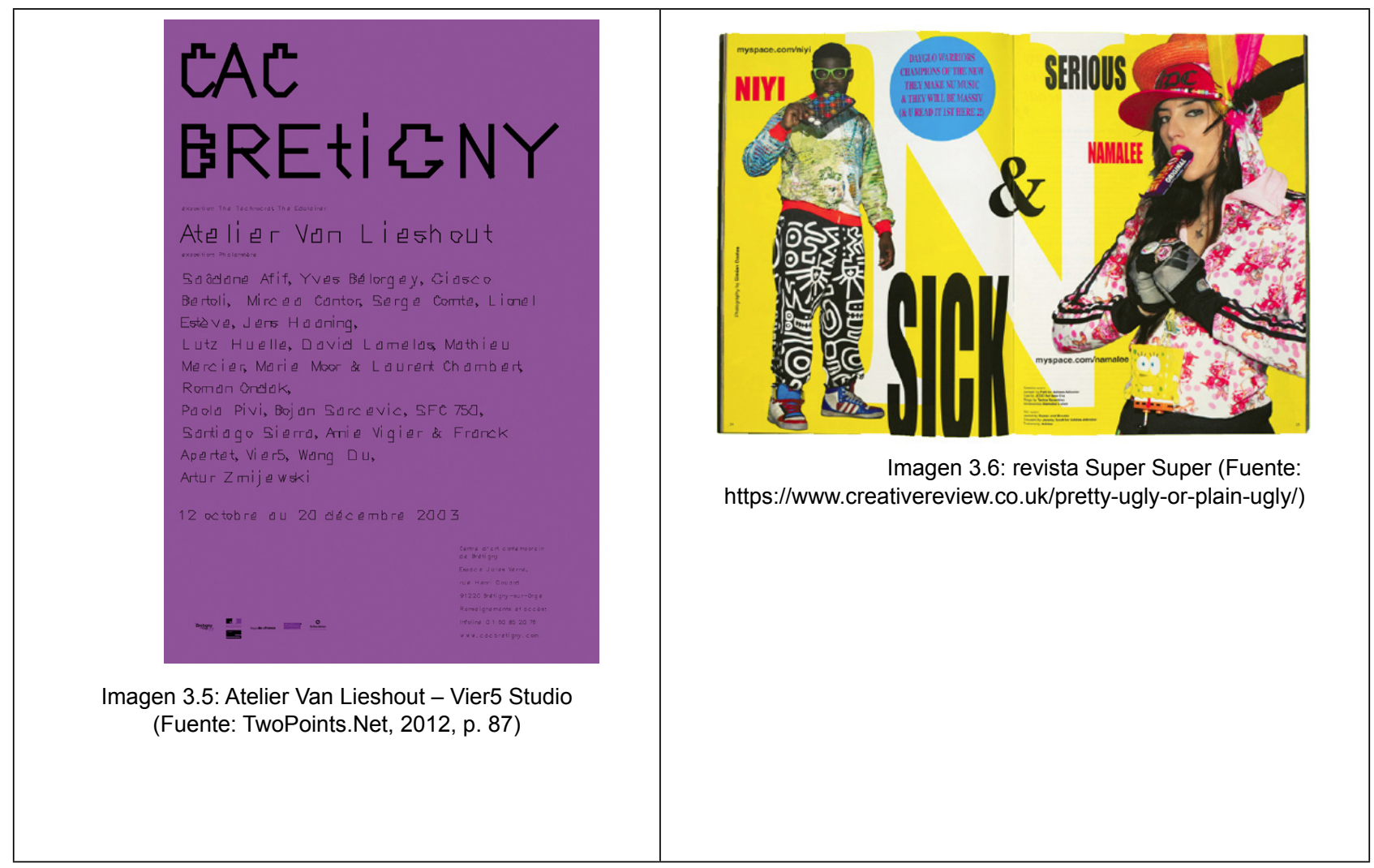

\section{La tipografía como signo visual desde la semiótica}

La tipografía es una realidad poliédrica que necesita ser considerada desde varias perspectivas para abarcar todas sus implicaciones. Una fuente tipográfica es signo (significante y con significado), signo lingüístico cuando con ella se componen palabras y frases, y realidad plástica con color, forma y textura. Una perspectiva semiótica de la tipografía facilita identificar en ella factores visuales que "generan estados emocionales y permiten la asunción de valores que de cierta forma favorecen la interpretación de un texto" (Pérez Peña, 2010). La tipografía tiene, por tanto, elementos plásticos con implicaciones en su uso, por lo que, queda patente, que esos aspectos añaden al mensaje lingüístico elementos externos al mismo que bien pueden redundar en él o aportar matices e, incluso, nuevos significados para el lector. De esta forma, podemos hablar de la posibilidad de un valor agregado por cada tipografía al mensaje, entendido ya éste desde dos perspectivas cuando hablamos del uso tipográfico: el mensaje lingüístico y el visual. Se configura la tipografía, así, como un sistema pluricódigo (lingüístico y visual) (Pérez Peña, 2011, p. 276). En ese sentido, es aplicable la teoría de la transcodificación de Klinkenberg (2006, p. 211), que entiende que un mismo significado puede transitar diferentes sustancias de la expresión. Por lo tanto, la escritura - y también la tipografía - cumpliría una función grafemológica (además de una gramatológica) que une la lengua y su representación.

Saussure entendía los símbolos lingüísticos como abstractos y convencionales, por lo que cada tipo dentro de una familia tipográfica es una representación de la noción abstracta que hemos convenido para 
cada letra. Así, una letra existe, simbólicamente, como abstracción que un grupo humano acepta y comparte, pero para dar forma a la escritura la plasmamos visualmente, creando la fuente tipográfica (o escribiendo a mano, lo que daría lugar a la letra dibujada). Esa plasmación debe contener los rasgos esenciales que la identifican como una letra concreta, pero en ese acto existe un rango de libertad que mientras no la haga irreconocible posibilita numerosas formas de traslación al mundo plástico. Además, también hay margen para añadir elementos a la tipografía que no estén entre los rasgos básicos que componen la concepción abstracta de la letra.

En ese sentido, se puede plantear la posibilidad de una tipografía neutra, es decir, cuyos rasgos plásticos no añadan nada al mensaje lingüístico. Existen teorías que consideran que ese mensaje puede ser neutro si el tipógrafo se ciñe totalmente a las reglas que determinan la convención para cada letra (Jury, 2007, p. 72). Desde aquí descartamos ya esa posibilidad, puesto que esas reglas no son rígidas sino que, en cuanto abstracciones, aplicarlas significa interpretarlas, siempre y cuando continúen siendo reconocibles los rasgos que configuran una letra concreta. Por lo tanto, como afirma Pérez Peña (2010, p. 12): "encontrar un valor semiótico en las características plásticas de la tipografía sí es posible". En ese sentido, Gordon y Dodd (1994) entienden que las características de las letras dotan de personalidad a la tipografía, por lo que la elección de una u otra por parte del diseñador busca "iluminar el texto" (Bringhurst, 2008, p. 117).

Otra cosa es la interpretación del receptor del mensaje y la emoción que la tipografía puede despertar en él, donde interviene la subjetividad y la condición previa de dicho receptor. En ese sentido, esta fase de producción emotiva de una tipografía se ve imbuida de aspectos subjetivos que hacen difícil su estudio, lo que no significa que existan procesos de reconocimiento externo de una fuente tipográfica (es decir, de valoración externa a las intenciones de su creador y aquel que la utiliza en un texto), que atienden a convenciones y usos plásticos y comunicativos asentados y generalmente reconocidos (por ejemplo, la tipografía de la señal de stop la asimilamos a una orden por costumbre y, así, sus aspectos emocionales son aprendidos). De esta forma, la desconexión de la tipografía de cualquier elemento figurativo, que deviene de su carácter inevitablemente convencional, hace que la legibilidad de una tipo esté muy relacionada con la costumbre, ya que, quitando casos donde se dificulta deliberadamente la legibilidad — es tras verla habitualmente que identificamos una tipografía como legible frente a otra a la que no estamos acostumbrados (Gill, 2004, p. 62).

Por lo tanto, se puede afirmar que la tipografía mantiene una relación con el mensaje lingüístico, aunque sea aleatoria —dándose lo que Greimas (1994) califica de codificación débil—, a partir de la cual se puede estudiar la relación entre sus elementos plásticos y el signo lingüístico.

\section{Análisis comunicativo del recurso tipográfico de la campaña}

El objeto de análisis del presente trabajo es el uso tipográfico de la campaña visual que el Ayuntamiento de Madrid encargó a Koln Studio para publicitar la celebración del Madrid World Pride 2017. El World Pride (u 
Orgullo Mundial) es una celebración internacional que busca festejar los avances obtenidos en la lucha por los derechos de lesbianas, gais, bisexuales, transexuales, intersexuales y, recientemente, la comunidad queer (muchas veces denominados, genéricamente, como comunidad LGTBIQ).

La campaña se compone de varias piezas graficas con diferentes adaptaciones. Su eslogan fue "La diversidad es el orgullo de Madrid", relacionando la histórica naturaleza de la capital española como ciudad de acogida de emigrantes de todos los rincones de España y el mundo, con la libertad y la diversidad de opciones sexuales y formas de vida que implica el movimiento LGTBIQ y la propia fiesta del Orgullo.

Como señalan los diseñadores (Daniel Fuente, Pablo Mariné, Pablo Huertas y María P. Trillo), ya desde el briefing se optó por una solución tipográfica y el predominio del blanco y negro frente a la estética usual en las campañas de este tipo de celebraciones, generalmente basadas en la imagen y los omnipresentes colores de la bandera gay. Así, el estudio recurrió a la tipografía Lÿno, creada por Radim Pesko y Karl Nawrot en 2012, que utiliza cuatro estilos tipográficos que homenajean a corrientes estéticas del siglo XX, posibilitando infinitas combinaciones. En palabras de los diseñadores, la campaña trata de: "incomodar y generar debate, reflejando así el carácter inconformista, alegre y provocativo del Orgullo. El resultado es una campaña tipográfica en la que la forma y el significado se dan la mano para representar los valores del Ayuntamiento de Madrid y el colectivo LGBTIQ" (Koln Studio, 2016).

\subsection{La tipografía Lÿno}

La tipografía Lÿno destaca por no ser una tipográfica única, sino que se compone de cuatro estilos tipográficos que se pueden combinar de la forma que se desee. Concretamente, contiene las fuentes Jean (Arp), Stan(ley Kubrick), Ulys(ses 31) y Walt (Disney). Cada una remite a una estética concreta del siglo XX: la escultura biomórfica de Jean Arp, la estética retro de Stanley Kubrick, la tipografía utilizada en los créditos de la serie de animación japonesa Ulysses 31 - que remite a la estética asociada a las tipografías griegas-y las formas redondeadas de la tipografía del logo de Walt Disney.

Los cuatro estilos tipográficos tienen una significativa conexión con formas escultóricas, son pesados y eminentemente de caja alta (mayúsculas), en línea con la metodología de trabajo de Karl Nawrot. Éste encara el diseño tipográfico desde una perspectiva escultórica, partiendo del pincel y el dibujo y llevándolo a modelos en tres dimensiones de plástico o planchas de foam que proyectan un aspecto muy orgánico. Pero la principal característica de la Lÿno es la intercambiabilidad de los caracteres — gracias a su gestión digital—, es decir, la posibilidad de aplicar a cada carácter un estilo tipográfico diferente de entre los cuatro disponibles, que la hace, en palabras de uno de sus autores, "open and various, and their spirit is this: to resist normative tendencies and to reject the idea of definitive form" (Pesko, 2017). Estamos, por tanto, ante la posibilidad de un alfabeto inestable que abre enormes posibilidades expresivas. 
5.2 Análisis de los atributos formales y la anatomía de los caracteres de los estilos tipográficos

- Jean (Arp)
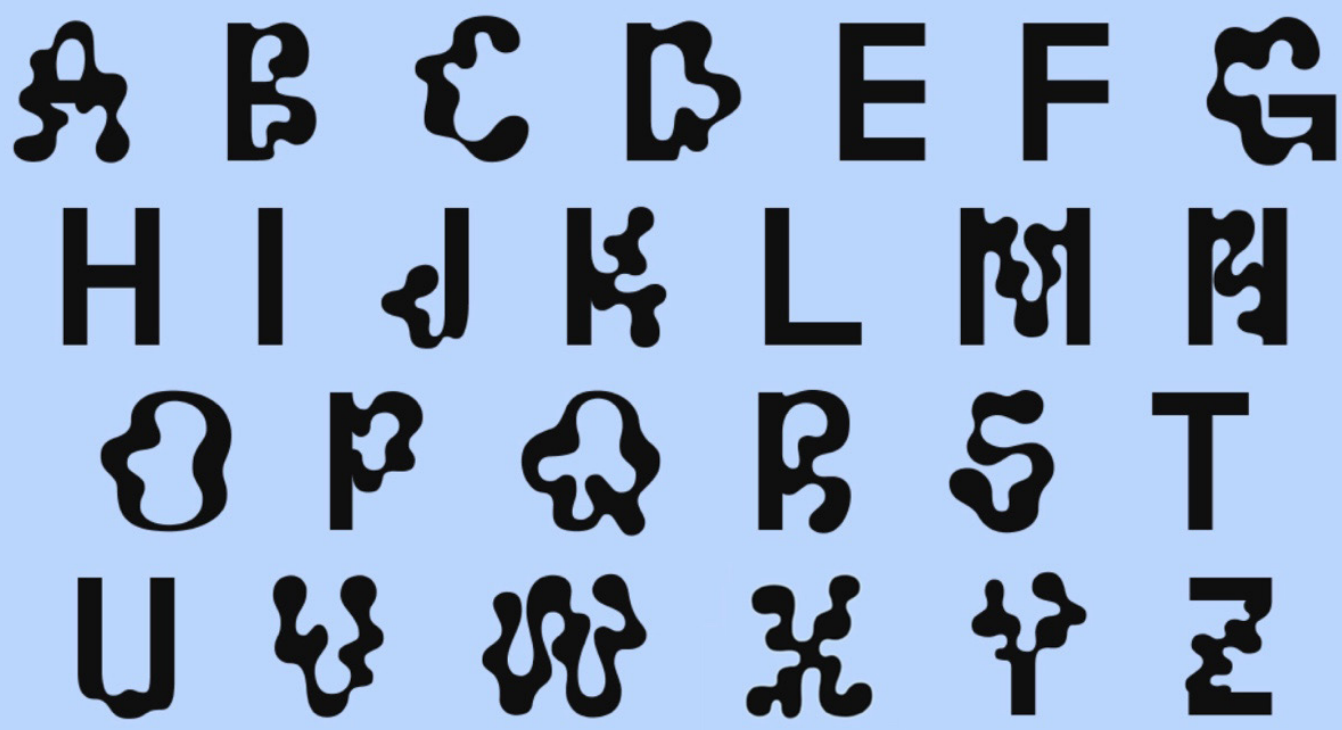

Imagen 5.1: Estilo Jean (Arp) caja alta (Fuente: https://radimpesko.com/fonts/lyno)

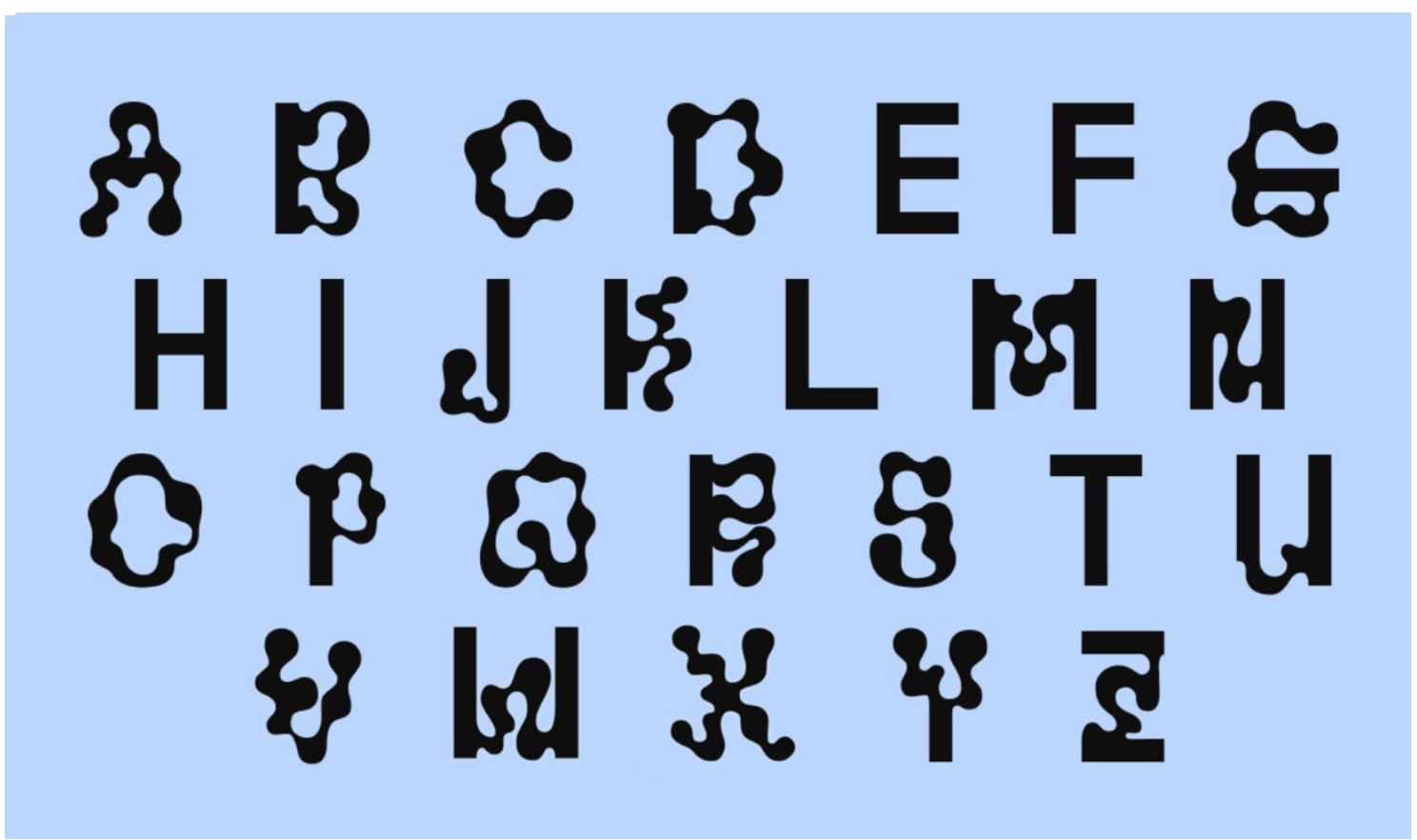

Imagen 5.2: Estilo Jean (Arp) caja baja (Fuente: https://radimpesko.com/fonts/lyno) 
El estilo Jean (Arp) se caracteriza por tener dos tipos de caracteres. Por un lado, los de estilo orgánico, que remiten a la ya mencionada escultura biomórfica de Jean Arp (letras A o C) (ver imagen 5.3), y por otro, de palo seco, muy racionales (como la $\mathrm{H}$ o la I). El estilo presenta caracteres de caja alta y baja, pero la pertenencia a una u otra categoría no la da la altura de la $x$, ya que ambas son iguales, sino que les distingue pequeños detalles en determinados caracteres que aportan más posibilidades al diseñador (imágenes 5.1 y $5.2)$.

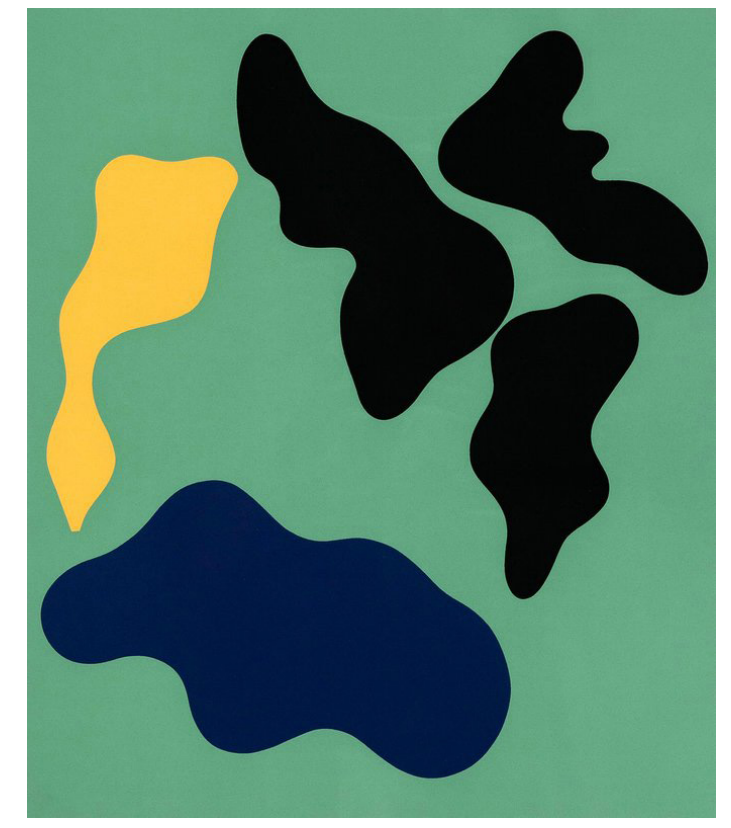

Imagen 5.3: Composition 1 - Jean Arp

(Fuente: https://www.artspace.com/jean-hans-arp/composition-1)

En el caso de los caracteres que recuerdan al artista, abundan los que combinan trazos de formas onduladas con barras que tienen una naturaleza recta como la $\mathrm{B}$ o la $\mathrm{D}$ de caja alta y baja y la $\mathrm{W}$ en la caja baja. En cambio en las letras $C, O, Q \circ X$ de caja alta y baja, las formas fluyen con toda libertad. En las partes onduladas se da un alto grado de modulación, ya que se producen cambios de grosor en el trazo constantemente. También se produce contraste en algunas letras entre los trazos más finos y otros más gruesos. Con relación al eje, los caracteres que están parcialmente distorsionados lo mantienen recto, mientras que los que están totalmente distorsionados tienen distintos grados de inclinación sin responder a una regla general. Por ejemplo, en la caja alta se puede observar que la $O$ y la $Q$ se inclinan hacia la derecha y la $\mathrm{V}$ hacia la izquierda.

Con respecto a la tipografía con trazos rectos, al tener el mismo grosor no muestran ninguna modulación, tampoco contraste en las diferentes letras y por este motivo, no tiene eje constructivo de contraste. Finalmente, ninguno de los estilos tiene remates o serifas, y en lo relativo a la proporción la anchura es entre condensada y normal. 
De esta forma, el autor parece querer jugar con los contrastes que se generan entre los trazos más rectos y los más curvos para transmitir una doble lectura: por un lado de seriedad, rigidez y por otro de libertad o juego que genera esa construcción de formas. De hecho, da la sensación de que la tipografía fue creada en el estilo racional y posteriormente se manipularon y deformaron ciertas partes de la letra intentando imitar el estilo de Arp.

\section{- Stan(ley) Kubrick}

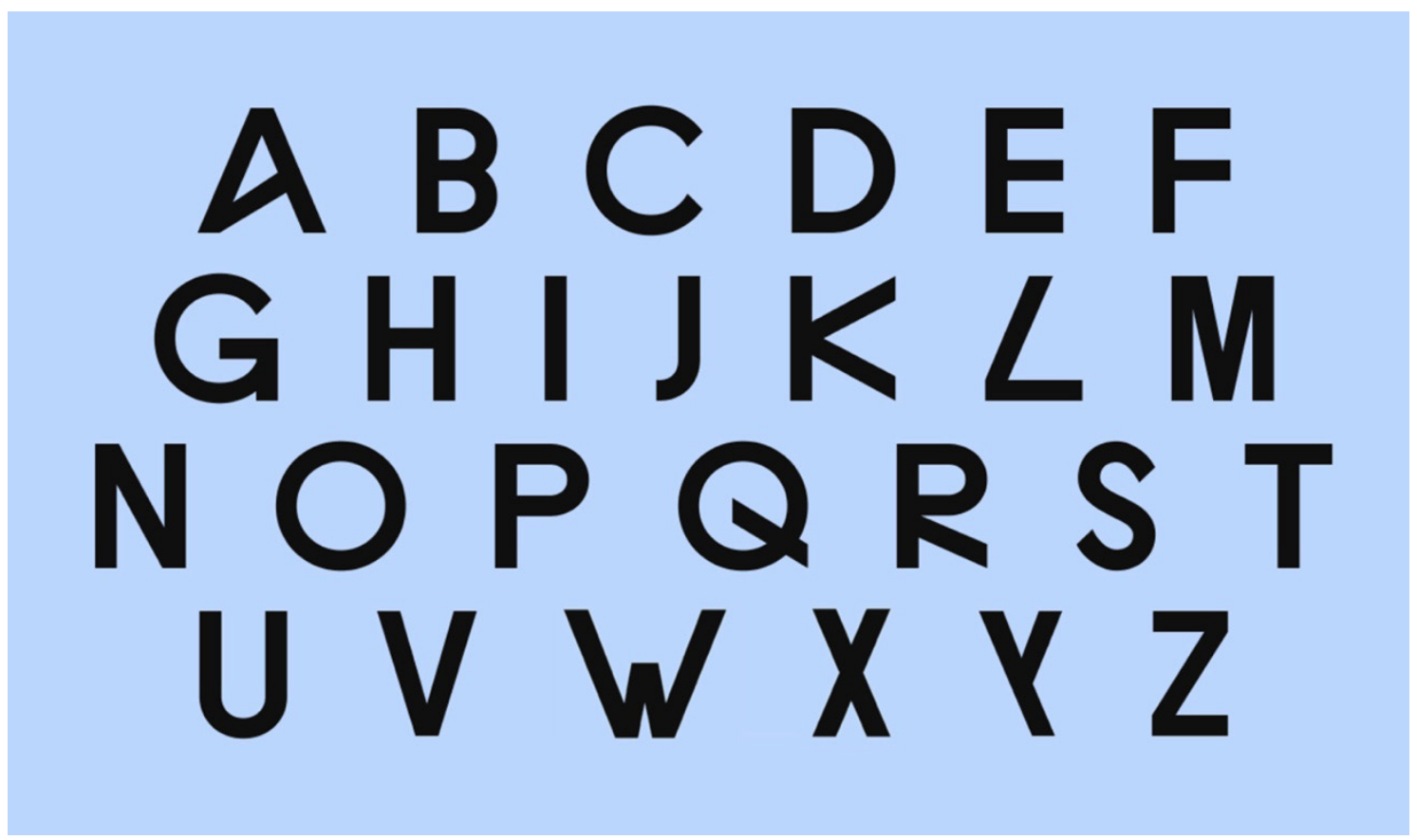

Imagen 5.4: Estilo Stan(ley) Kubrick caja alta (Fuente: https://radimpesko.com/fonts/lyno)

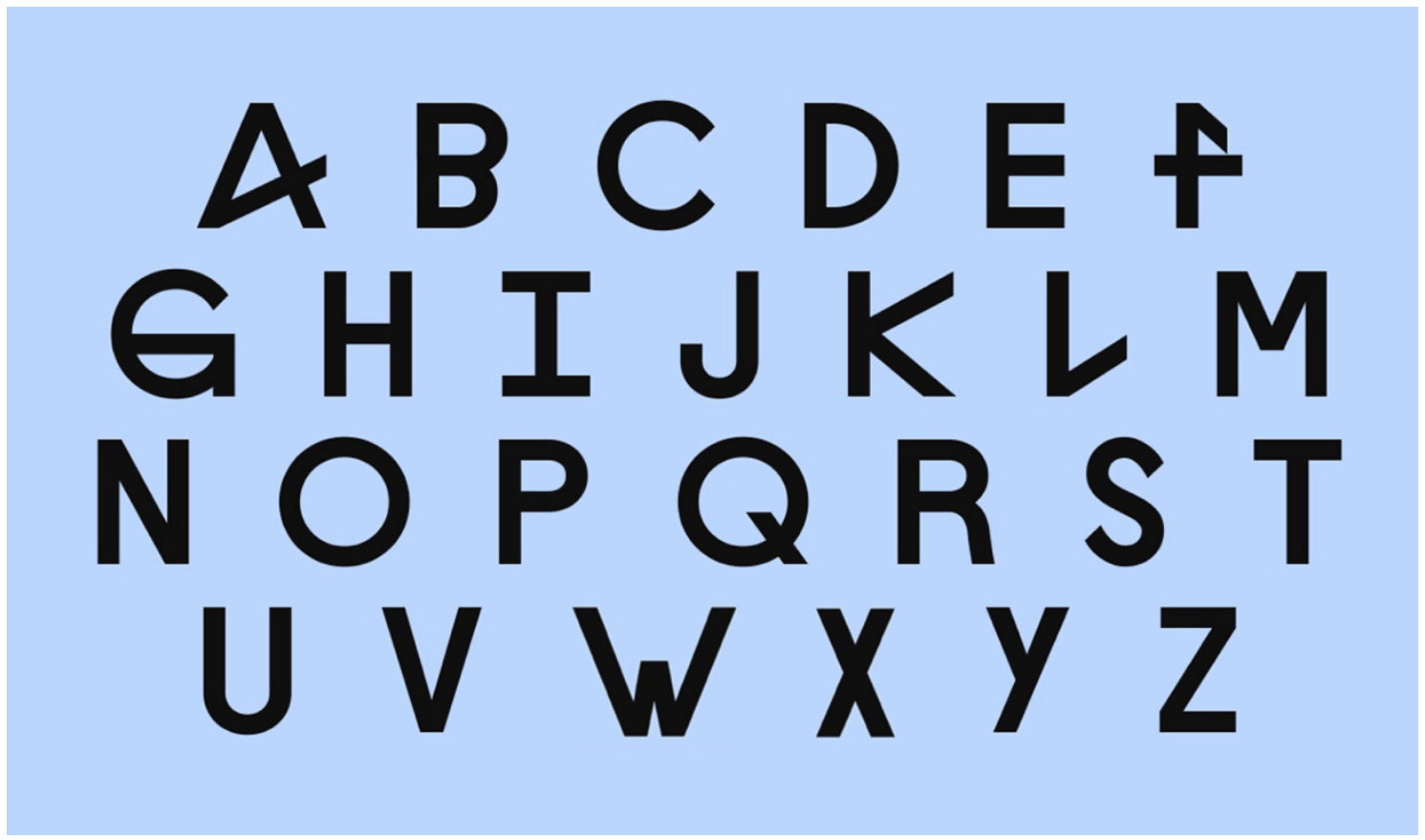

Imagen 5.5: estilo Stan(ley) Kubrick caja baja (Fuente: https://radimpesko.com/fonts/lyno) 
El estilo Stan(ley Kubrick) es una tipografía con apariencia geométrica y racional, de inspiración cercana a la Bauhaus y detalles que recuerdan al Art Decó y a tipografías como la Futura. Así, en ella predomina la recta, pero es muy redondeada en las partes curvas, creando grandes contraformas que propician la legibilidad.

Al igual que ocurría con el estilo Jean (Arp), los diseñadores hacen una distinción entre caja alta y baja muy sui géneris, ya que la diferencia entre una y otra sólo se da en pequeños detalles que tienen que ver con el trazo (nótese ambas aes o emes, el brazo de la F de caja baja, que se inclina, el filete o perfil de la G de caja baja, que se alarga con respecto al de la caja alta, el efecto de la contraforma superior de la B de caja baja que recuerda al estilo Art Decó, etcétera). De esta forma, la altura de la x no es pertinente ya que no existen ascendentes ni descendentes en ninguno de los estilos (imágenes 5.4 y 5.5 ).

En cuanto al trazo, no existe modulación alguna y, por lo tanto, no hay contraste en los grosores, así como, tampoco, ninguna inclinación en el eje. El espesor o grosor de las letras y su color es medio, así como su mancha. Sólo tienen una serifa en la I de caja baja cuyo pie es catalogado de uniforme.

Por último, respecto de la proporción, la anchura de los caracteres es media en general, sin embargo es prominente en las letras dotadas de forma circular (C, G, O ० Q).

- $\quad$ Ulyss(es) 31

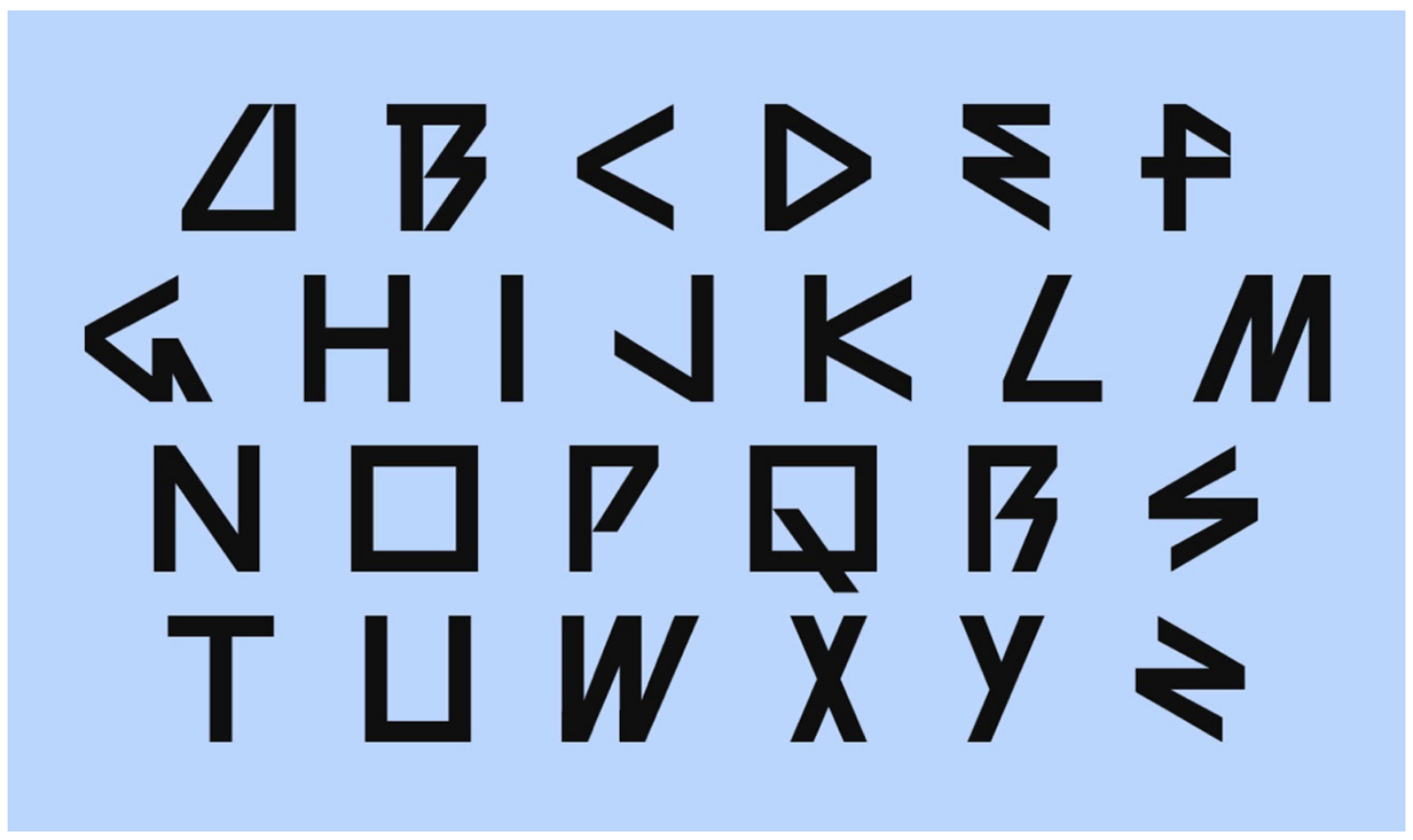

Imagen 5.6: estilo Ulis(ses 31) caja alta (Fuente: https://radimpesko.com/fonts/lyno) 


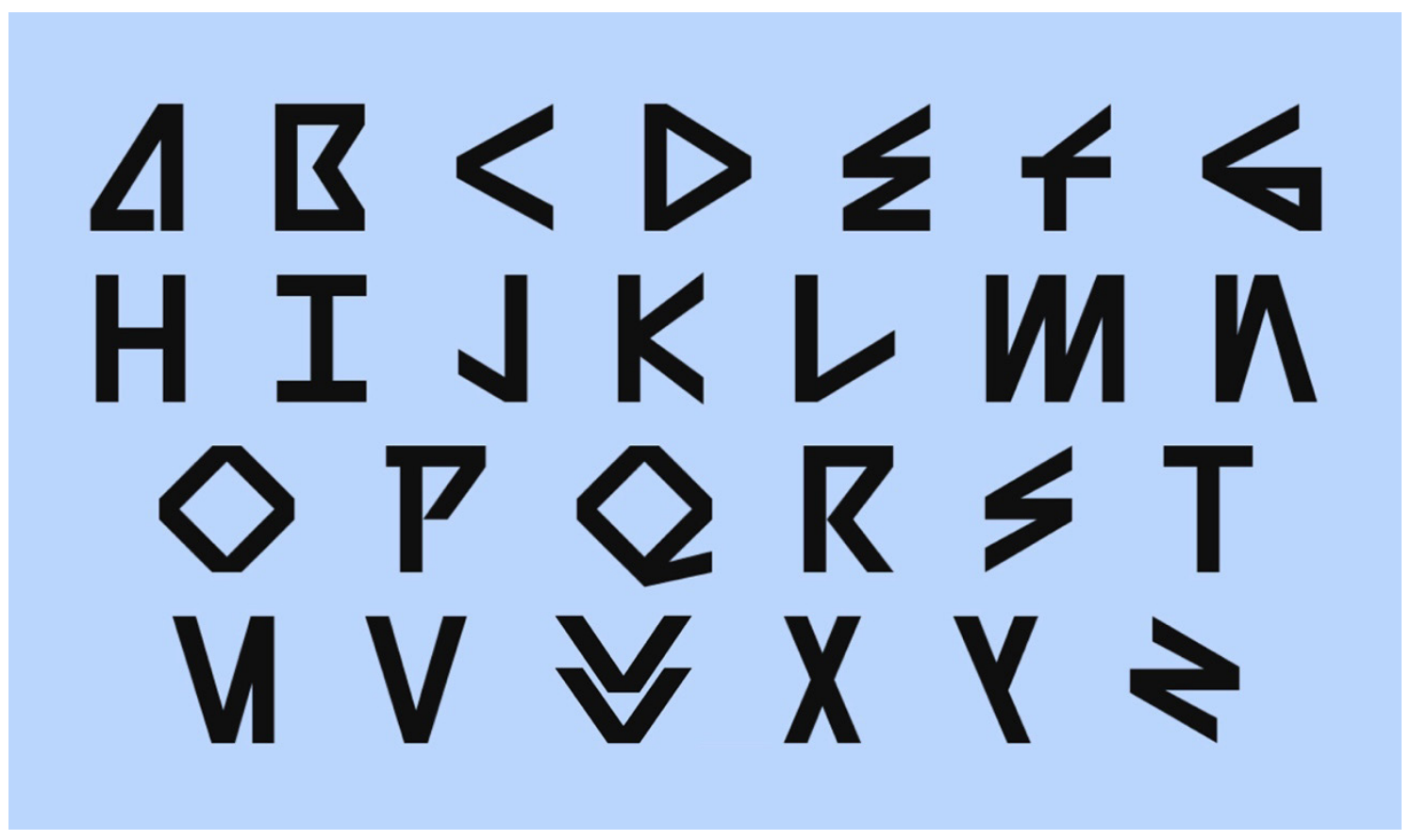

Imagen 5.7: estilo Ulis(ses 31) caja baja (Fuente: https://radimpesko.com/fonts/lyno)

Este estilo recrea la estética de las formas del alfabeto clásico griego, en sus trazos rectos y en sus composiciones cuadradas y triangulares — sin curva alguna-, añadiendo cierto aspecto modular que le confiere una estética más moderna.

Contiene dos familias correspondientes a la alta y baja, pero la diferencia entre ambas tiene que ver con el cambio de disposición u orientación de algunos trazos que dan lugar a formas más cuadradas o triangulares , por ejemplo, la $\mathrm{O}, \mathrm{Q} \circ \mathrm{V}$ de caja alta son cuadradas, mientras que esos caracteres en la caja baja son triangulares o de ángulo agudo, como la $\mathrm{V}$ (imágenes 5.6 y 5.7 ).

En consonancia con la rigidez de los anteriores rasgos, el trazo no genera ninguna modulación, no tiene contraste y tampoco inclinación del eje alguna. El espesor de las trazos es medio y la tipografía colorea medianamente. No contiene serifas, únicamente la I de caja baja tiene un pie uniforme, y la B de caja alta y la P de caja baja tienen una pequeña prolongación del trazo llamada espolón. En relación a las proporciones, su anchura es media porque las formas son mayoritariamente cuadradas. 
- Walt (Disney)

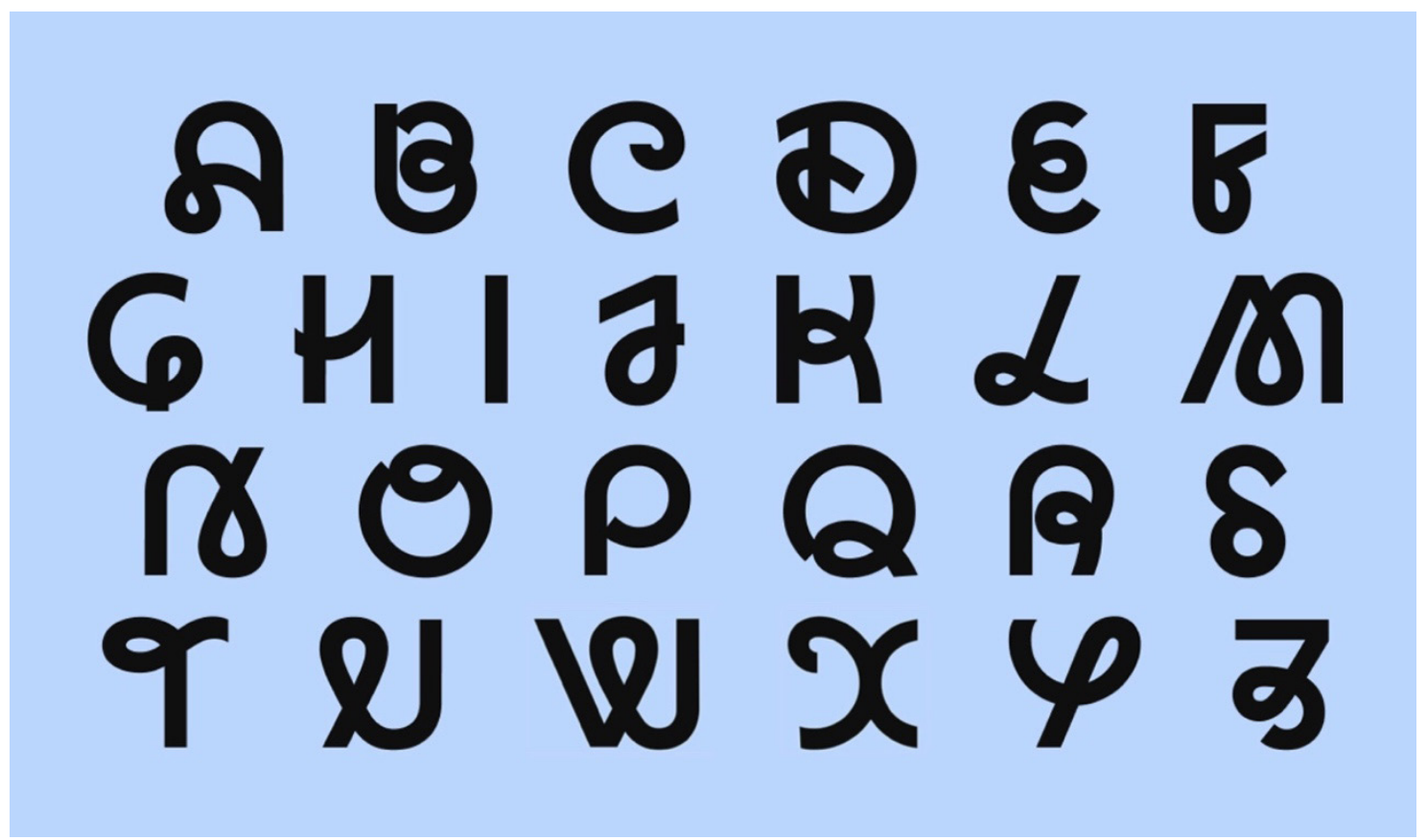

Imagen 5.8: estilo Walt (Disney) caja alta (Fuente: https://radimpesko.com/fonts/lyno)

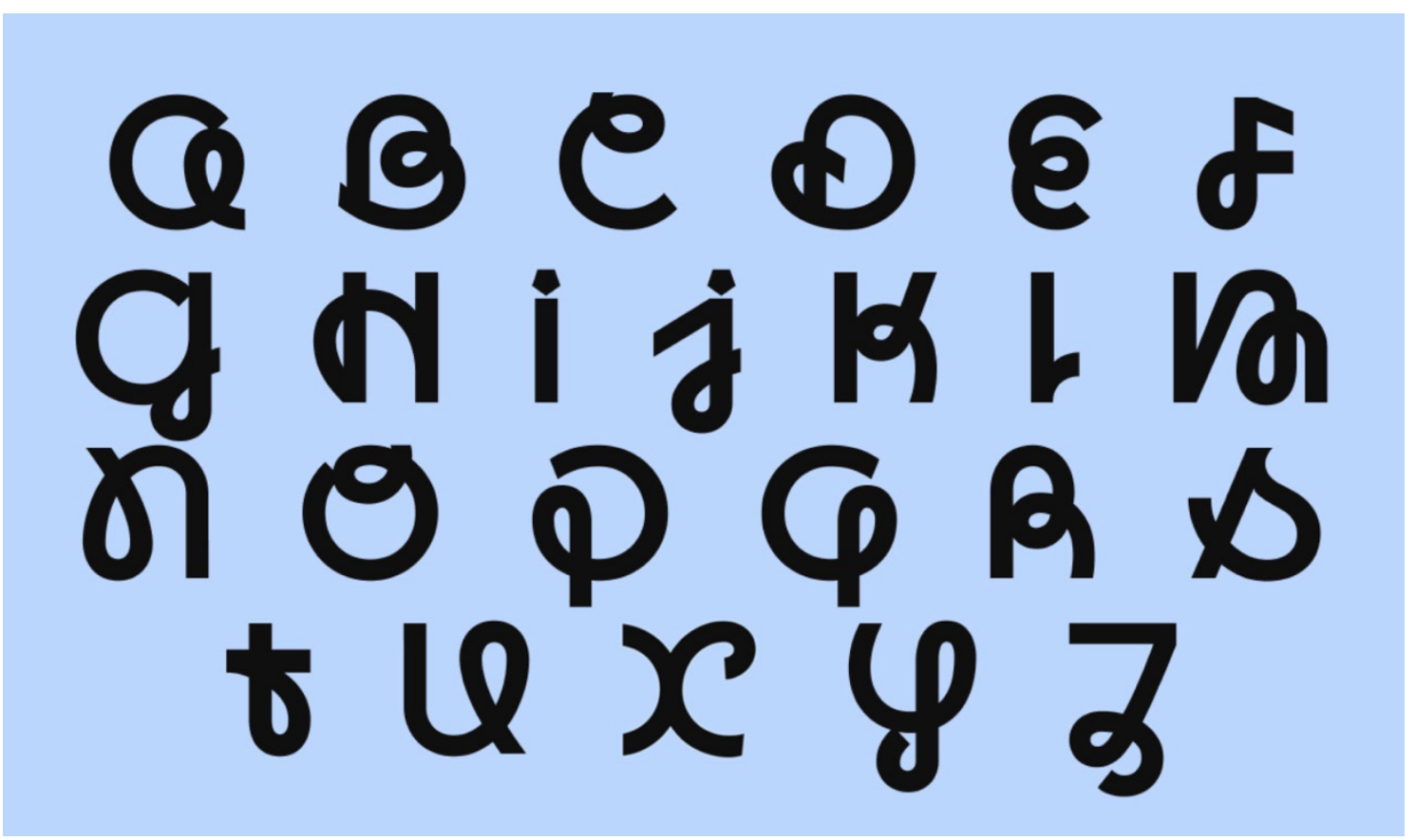

Imagen 5.9: estilo Walt (Disney) caja baja (Fuente: https://radimpesko.com/fonts/lyno)

El estilo Walt, como su nombre indica, encuentra inspiración en las formas caligráficas y redondeadas del logo de la compañía Disney. Este homenaje se traduce en una tipografía que parece hecha a mano, dotada de bucles en muchas partes de los caracteres y cuya diferencia principal con respecto al original es la limpieza y perfección en sus trazos, fruto de su producción digital. Como en los casos anteriores, los estilos 
de caja alta y baja son de la misma altura, y muchos de sus caracteres son prácticamente idénticos, variando algún pequeño detalle de orientación, posición o diseño (imágenes 5.8 y 5.9).

El espesor del trazo es el mismo en toda la letra por lo que no existe modulación, tampoco contraste, ni eje constructivo de contraste. El grosor de las letras es medio, así que su color también lo es. La característica que mejor define esta tipografía es la repetición del bucle en diferentes partes de las letras. Así, en la B, E, K y $R$ de caja alta y baja se encuentra en el filete, mientras que en la $A, N, U$ y $Y$ de caja baja se encuentra en el asta. También se puede identificar un espolón en algunos caracteres como la B, D de caja alta o la C, G u $\mathrm{O}$ de caja baja. Por último, las dimensiones proporcionales de esta tipografía denotan una anchura de media a grande.

\subsection{Análisis semiótico de la campaña}

Las piezas que conforman la campaña se estructuran en torno a un eslogan que adopta cuatro formas: la diversidad/los derechos/la libertad/ la igualdad es el orgullo de Madrid. De esta forma, las diferentes piezas combinan esos términos para generar el mensaje lingüístico.

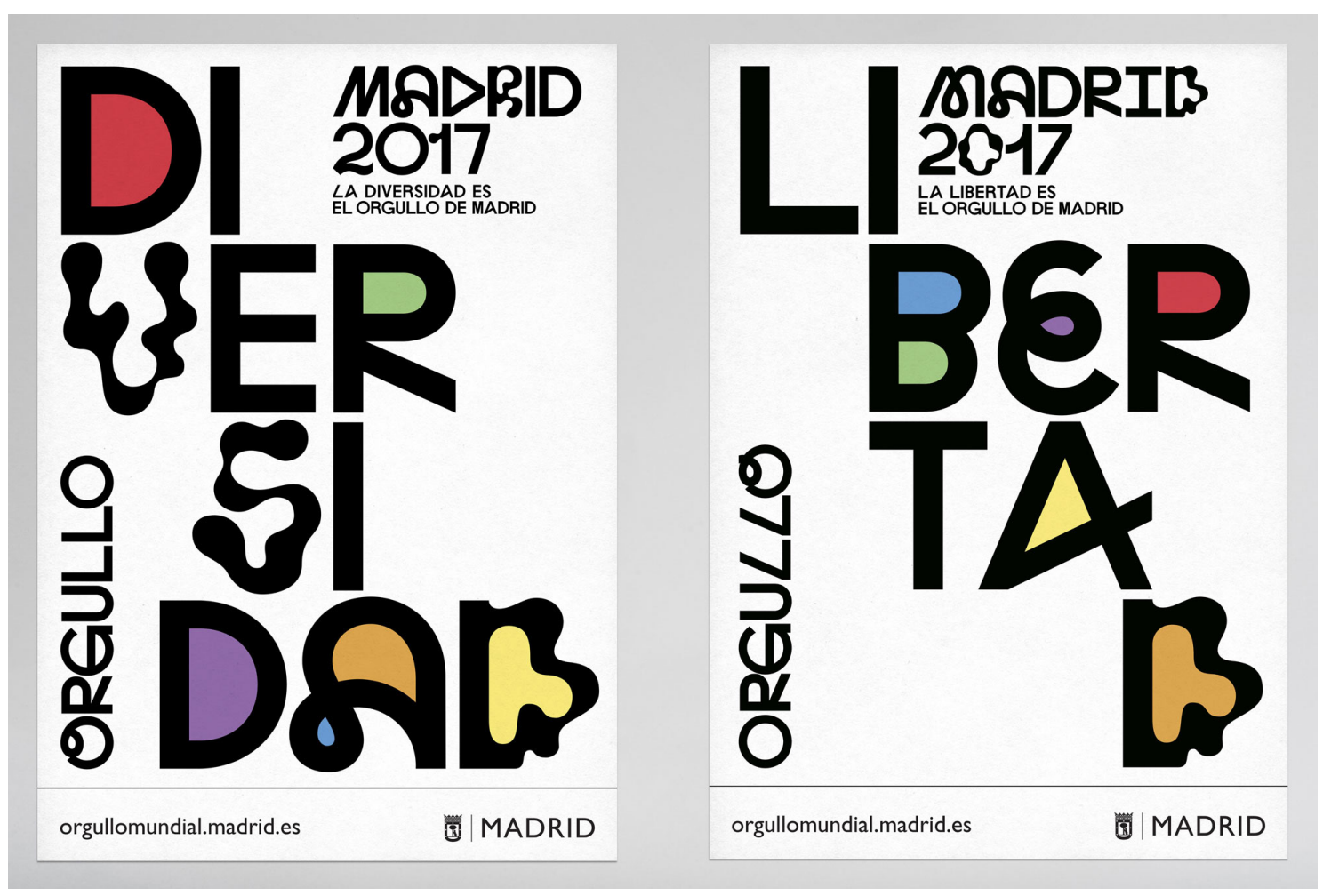

Imagen 5.10: carteles World Pride 2017 (http://kolnstudio.com/orgullo-es)

Para analizar el uso de la tipografía como signo plástico recurriremos a tres piezas de las que componen la campaña y que muestran todos sus recursos. La metodología de análisis del signo visual desarrollada por el Groupe $\mu$ indica que el primer elemento que se ha de analizar es la forma, que incluye el estudio de los formemas (dimensión, posición y orientación, que se unen para construir una significación en la forma). La dimensión se valorará según el eje semántico de la dominancia, que bascula entre lo dominante 
y lo dominado. Como se puede ver en las imágenes de referencia (5.10, 5.11 y 5.12), la dimensión de los caracteres tipográficos en la composición es muy grande, pudiéndose apreciar la dominancia de los términos que componen el sujeto del eslogan (diversidad, derechos, libertad e igualdad) lo que, inicialmente, aporta al mensaje una gran rotundidad. En ese sentido, el tamaño de los caracteres, junto al espesor considerable del trazo, facilita la transmisión del mensaje, su legibilidad. Así, se puede afirmar que se busca transmitir el mensaje de manera categórica, en consonancia con la construcción del eslogan.

Pero al tamaño de los caracteres hay que sumar su aspecto formal, ya analizado, y la combinación de estos en el resultado final. Como se explicó, la Lÿno es una tipografía mutable y, por lo tanto, sin forma final, debido a las innumerables combinaciones que permiten sus cuatro estilos. De esta manera, el uso del estilo Jean (Arp) añade cierto grado de confusión por sus formas ondulantes, como lo hace la combinación de los caracteres de los diferentes estilos, provocando que el lector deba realizar un esfuerzo en la identificación del mensaje lingüístico. Si la legibilidad está ligada a la costumbre en el reconocimiento de la tipografía (Gill, 2004), la combinación de caracteres de diferentes estilos tipográficos en un mismo texto (imagen 5.11), e incluso en una misma palabra (imágenes 5.10 y 5.12) actúa directamente contra ella, ya que son prácticas que rompen con los usos tipográficos habituales, aunque los caracteres de casi todas los estilos utilizados (excepto lo más deformados del estilo Jean (Arp)) posean características que facilitan su legibilidad (contraformas amplias, buen contraste entre forma y contraforma, etcétera).

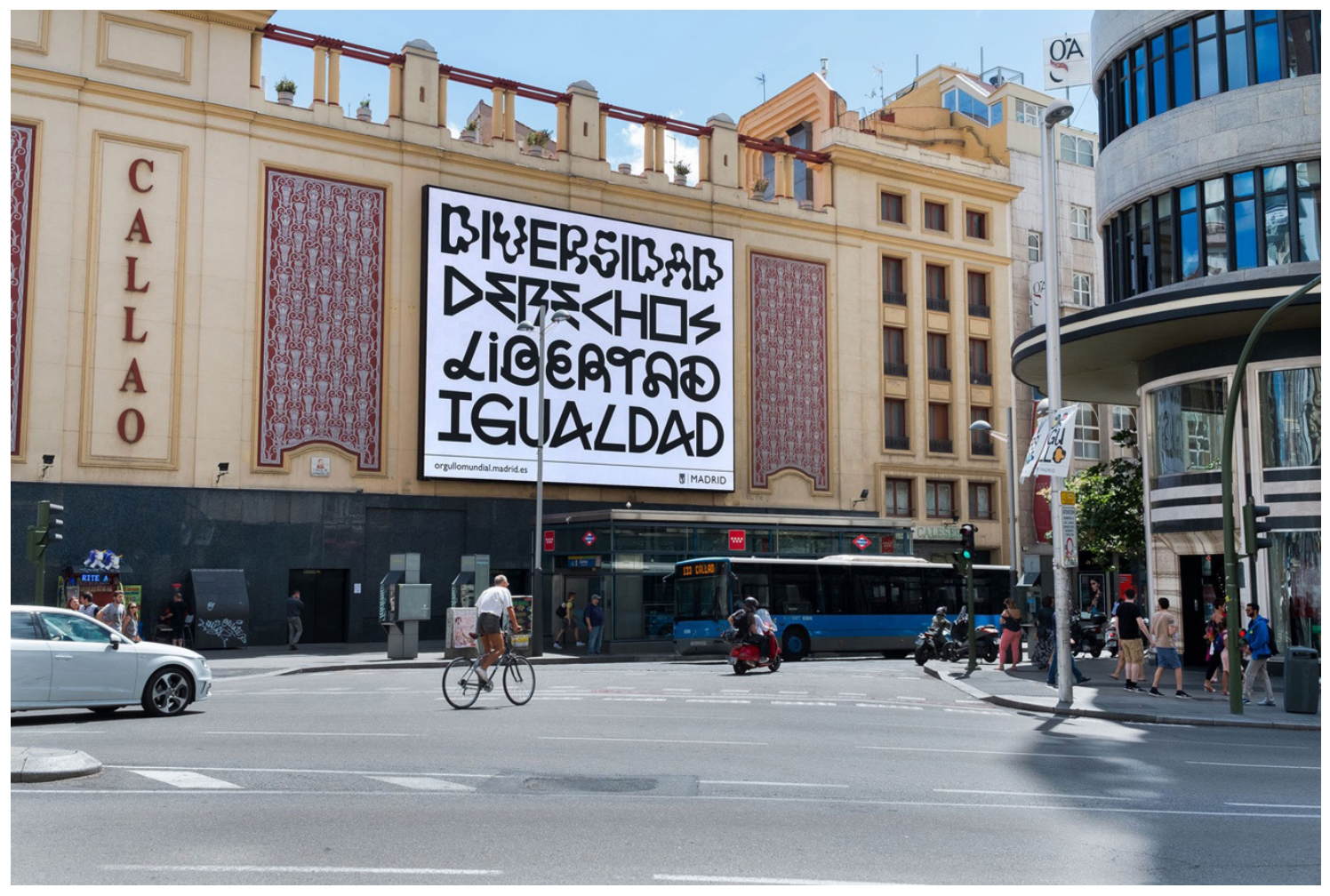

Imagen 5.11: cartel World Pride 2017 (http://kolnstudio.com/orgullo-es)

El segundo formema será la posición "relativa a un fondo o un foco o lugar geométrico de la percepción. El formema de la posición [...] establece la oposición vertical-horizontal-oblicuo y, a partir de esta oposición se generan los ejes semióticos que pueden describir una forma" (Pérez Peña, 2010, p. 20). A estos ejes hay 
que añadir el rasgo de la dirección: hacia arriba, hacia abajo, central, marginal, centrípeto y centrífugo. En ese sentido, podemos decir que la posición de las manifestaciones tipográficas es, eminentemente central en todos los ejemplos, ya sea ocupando la diagonal central, como en la imagen 5.10, todo el espacio (imagen 5.11) o la vertical central (imagen 5.12), lo que hace a la forma fuerte y estable. Pero también es importante resaltar que en la imagen 1 se rompen las palabras sin respetar, incluso, las sílabas, distribuyendo los trozos de forma diagonal en el cartel y provocando una sensación de dinamismo. Por lo tanto, la posición del texto varía en cada pieza, generando una sensación de indefinición formal que caracteriza el completo uso de la tipografía por parte de los diseñadores. Esto conduce al tercer formema: la orientación, que viene determinada por la estabilidad (vertical y horizontal) contra la potencialidad del movimiento, determinada por la diagonal. Como se puede apreciar imperan las líneas horizontales en los tres ejemplos, con alguna incursión en la verticalidad (imagen 5.10), lo que transmite equilibrio y estabilidad.

El segundo elemento que el Groupe $\mu$ considera es la textura, determinada por dos texturemas: los elementos y la repetición. Los elementos, identificados desde una perspectiva microtopográfica (muy de cerca) crearán la textura al repetirse y observar la fuente tipográfica desde mayor distancia. Ambos aspectos se combinan para crear la textura, que se manifiesta en la tridimensionalidad, la tactilomotricidad y expresividad. Es decir, que la textura de la tipografía es entendida aquí como el acercamiento a la tercera dimensión y a la fantasía del tacto por el signo plástico. En ese sentido, la tipografía utilizada posee escasas cualidades, y los creativos de la campaña tampoco se las han querido conferir añadiendo detalles a la misma. Por lo tanto, se muestra que la tipografía se aleja, desde esta perspectiva (la textura), de cierta tradición de las tipografías decorativas y expresivas (aunque en otros aspectos puedan acercarse, como la ondulante deformación de algunos caracteres del estilo Jean(Arp), o los múltiples detalles del Walt(Disney)).

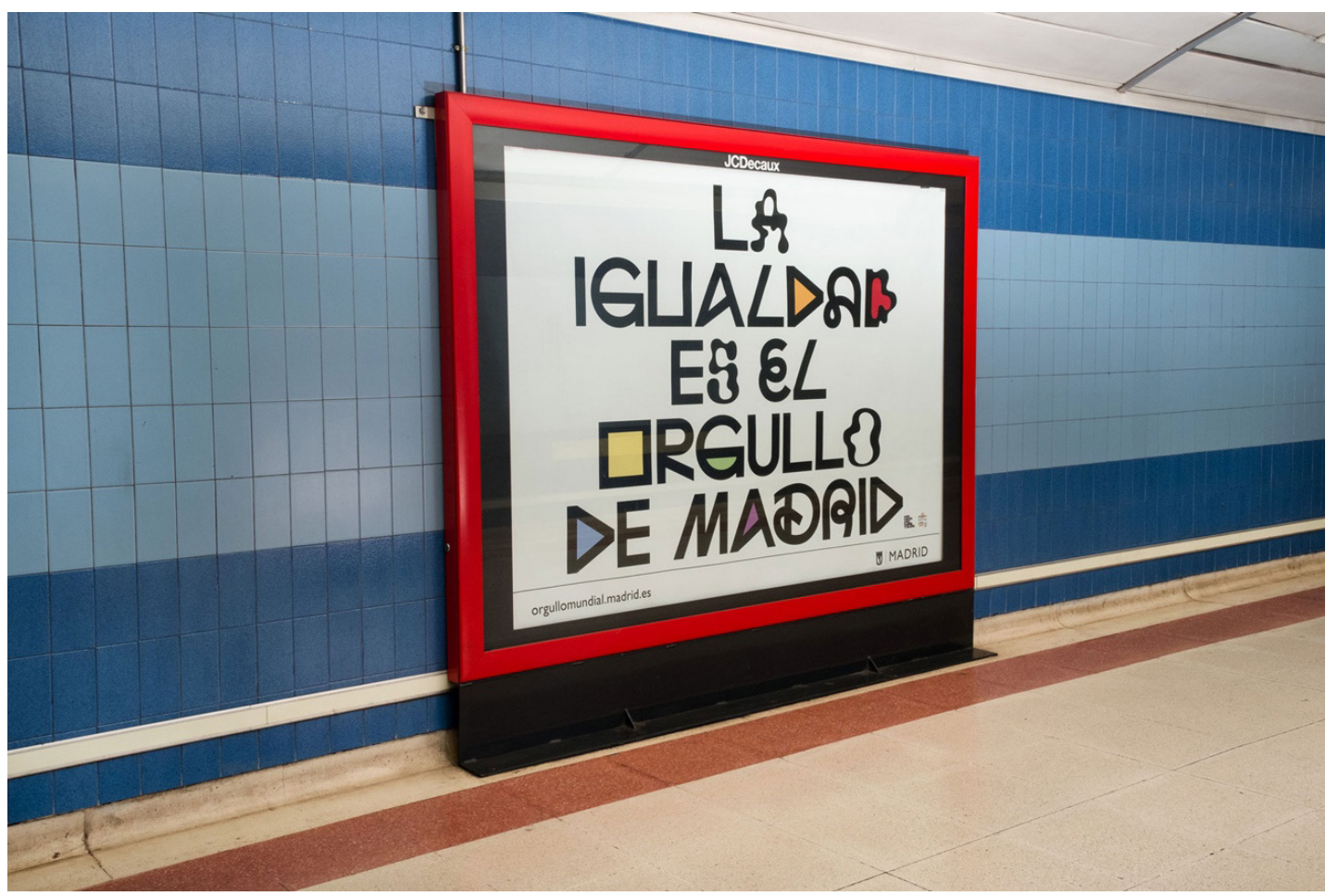

Imagen 5.12: cartel World Pride 2017 (http://kolnstudio.com/orgullo-es) 
Por último, el color cerrará el espectro de los elementos a analizar desde la perspectiva semiótica. Como los anteriores, el color se determina por sus cromemas, que son la saturación (que se mueve en el eje entre saturado e insaturado, transmitiendo energía o falta de ella), la dominancia (que trabaja en la oposición entre colores cálidos y fríos) y la luminosidad (que se determina por el grado de brillantez u opacidad), pero al utilizar el negro (la ausencia de color) no son valorables estos tres aspectos, ya que no posee esas cualidades.

El negro favorece la legibilidad del mensaje lingüístico, sobre todo por su contraste con el fondo blanco, su opuesto, pero hay que señalar que las contraformas de algunos caracteres (imágenes 5.10 y 5.12) se han rellenado con los colores propios de la bandera arcoíris, aunque los tonos utilizados no son especialmente saturados, contrarrestando la viveza y energía que usualmente trasmite esta bandera. Sorprende, así, la forma en que se ha relegado el color en una campaña relacionada con el movimiento LGBTIQ, donde se suele abusar de los colores de la bandera arcoíris.

\section{Conclusiones}

Tras el análisis de los atributos formales, así como el semiótico, se ha constatado que, si bien, la tipografía utilizada tiene aspectos relacionados con aquéllas conocidas como expresivas, al separar sus estilos, dichos rasgos no se muestran muy acusados: la textura inexistente y el color negro no remiten a este tipo de familias tipográficas, mientras que en sus aspectos formales encontramos ciertos elementos que pueden hacerlo (los ya mencionados en los estilos Jean y Walt), pero combinados con formas racionalistas, que tienden a la angulosidad, la rigidez y la regularidad.

Es en el uso de los caracteres donde se puede encontrar una concepción más libre y expresiva que rompe con las normas relativas a la legibilidad y los usos tipográficos funcionales. En la combinación de los caracteres se encuentra el potencial expresivo de la tipografía, que confiere al mensaje que con ella se compone de indefinición, desigualdad y extrañeza, al reunir diversos estilos y soluciones plásticas: líneas rectas y curvas, caracteres muy angulares y otros muy redondeados, formas onduladas y trazos rectos, etcétera. Así, la Lÿno no puede considerarse una tipografía que rompa con los usos tipográficos tradicionales, sino que los reúne, haciendo suya la querencia posmoderna por aglutinar varios estilos, despojándolos de sus raíces estéticas y culturales y mezclando referencias al arte culto con otras pop, los dibujos animados y el cine (tipos que remiten a la antigua Grecia, distorsiones propias de las tipografías expresivas del siglo XX, trazos redondeados propios de los dibujos animados de Walt Disney, etcétera). Es en este sentido en el que la tipografía Lÿno y la campaña se relacionan con el movimiento New Ugly, relación que permite entender mejor sus connotaciones sígnicas. En el uso de la Lÿno se pueden ver las continuas referencias al pasado mezcladas con el presente, la mezcla de lo analógico y lo digital, la ironía al utilizar los referentes, una falsa apariencia de imperfección, la querencia por lo experimental aunque implique la pérdida de legibilidad, etcétera, todas ellas características propias del New Ugly. 
Estos aspectos tienen una innegable faceta expresiva que ha quedado patente en el análisis del signo plástico, las piezas de la campaña hacen visible una sensación de contraste, contradicción, indefinición, continuo cambio y libertad, nociones íntimamente relacionadas con el mensaje lingüístico de la campaña y con los valores que se quieren asociar a la comunidad LGTBIQ y, por ende, a la ciudad de Madrid (ciudad abierta y receptiva con la diferencia). Es la libertad y el derecho a definir una identidad sexual no convencional, o a no definirla en ningún sentido (queer), lo que caracteriza al movimiento LGBTIQ. Éste es abierto (como indica la inclusión de nuevas identidades, como la ya mencionada queer) y, por lo tanto, nunca definido o acabado, y, también, contradictorio, ya que reúne múltiples sensibilidades dispares. En ese sentido, la igualdad de los diferentes (en derechos y libertades) y la oposición clásica entre libertad e igualdad, o entre diversidad e igualdad, patente en el mensaje lingüístico, también se expresa en el signo plástico. Por lo tanto, se puede considerar que ese signo plástico y el lingüístico caminan en la misma dirección, aunque esta sea indefinida, y el camino no tenga un final claro.

Por lo tanto, las piezas analizadas son un ejemplo de cómo la tipografía puede tener una capacidad sígnica suficiente como para articular una campaña publicitaria de impacto, y hacerlo de forma original, si se atiende a una de las estrategias creativas clásicas, la reunión de opuestos, la contradicción no resuelta en un contexto donde los contrarios cohabitan sin excluirse. Así, esta campaña es un rara avis en el espectro de los esfuerzos comunicativos en otras celebraciones mundiales del Orgullo, donde prima el recurso a los colores de la bandera arcoíris y a la imagen (fotografía e ilustración) como centro de atención para el espectador.

\section{Referencias}

- $\quad$ Baines, P. y Haslam, A. (2002). Tipografía: Función, forma y diseño. México: Gustavo Gili.

- $\quad$ Bringhurst, R. (2014). Los elementos del estilo tipográfico. México D.F.: Fondo de Cultura Económica.

- $\quad$ Filpe, M. M. y Guitelman, M. S. (s.f.). Acerca de la tipografía como signo visual. Encuentros y divergencias: De las vanguardias artísticas del siglo XX al diseño en la década de los 90. Recuperado de: http://www.tallercfilpe.com.ar/site/ images/taller2/lecturas/lecturas_tp3/tp3_la_tipografia_signo_visual.pdf

- $\quad$ Gill, E. (2004). Un ensayo sobre tipografía. Valencia: Campgráfic.

- $\quad$ Gordon, M. y Dodd, E. (1994). Tipografía decorativa. Barcelona: Gustavo Gili.

- Greimas, A. J. (1994). Semiótica figurativa y semiótica plástica. En G. Hernández Aguilar (Ed.), Figuras y estrategia: En torno a una semiótica de lo visual (pp. 17-42). México D.F.: Siglo XXI.

- $\quad$ Groupe $\mu$ (1992). Tratado del signo visual. Madrid: Cátedra.

- Jury, D. (2007). ¿Qué es la tipografía? Barcelona: Gustavo Gili.

- Klinkenberg, J. M. (2006). Manual de semiótica general. Bogotá: Fundación Universidad de Bogotá Jorge Tadeo Lozano.

- Koln Studio (2016). Orgullo: Ayuntamiento de Madrid: Campaña 2016-2017. Recuperado de: http://kolnstudio. com/orgullo-es

- Martín Montesinos, J. L. y Mas Hurtuna, M. (2001). Manual de tipografía: Del plomo a la era digital. Valencia: 
Campgràfic.

- $\quad$ Pérez Peña. N. C. (2010). Apuntes sobre semiótica en tipografía. Revista S. 4, 11-27.

- Pérez Peña. N. C. (2011). Significación plástica de la tipografía desde la mirada de la semiótica visual. Revista Kepes. (7), 269-288.

- $\quad$ Pesko, R. (2017). Lÿno. Recuperado de: https://radimpesko.com/fonts/lyno

- $\quad$ Poynor, R. (2003). No más normas: Diseño gráfico posmoderno. Barcelona: Gustavo Gili.

- Suárez Carballo, F., Martín San Román, J. R. y Galindo Rubio, F. (2014). Los rasgos tipográficos del movimiento New Ugly. Journal of Design Innovation and Technology. 1 (1), 33-54.

- TwoPoints.Net (2012). Pretty Ugly. Berlin: Gestalten. 